\title{
Dietrich Kurze
}

\section{Lob und Tadel der artes mechanicae unter besonderer Berücksichtigung des Speculum vite humane des Rodrigo Sánchez de Arévalo (1467) - mit drei Anhängen}

\author{
Knut Schulz - buius libri editori et collegae Berolinensi, sexagenario (17.XI. 1997)
}

In der Sparte „Fremdbewertung und Selbstverständnis im Wandel“ innerhalb eines Kolloquiums über „Verflechtungen des europäischen Handwerks vom 14. bis zum 16. Jahrhundert" müßte eigentlich auch die Frage gestellt werden nach dem Wachsen und Wandel der Wahrnehmung und Einordnung der Handwerke im Geflecht der spätmittelalterlich-frühneuzeitlichen Sozial- und Wissenschaftstheorien sowie auf dem weiten Feld der Seelsorge und der Didaxe in ihren überaus mannigfachen Ausprägungen. Und wer so fragt, wird auf der Suche nach Antworten bald merken, daß es nicht genügt, sich nur einem Quellentyp oder gar lediglich einer einzigen Quelle zuzuwenden, aber auch, daß er im wahrsten Sinne des Wortes mit "seinem Latein bald am Ende“ ist, weil die heranzuziehenden Texte nicht nur in der Sprache der Theologen und Gelehrten, sondern ebenfalls im Vulgare aller oder doch sehr vieler abendländischer Völker verfaßt sind. Es gälte also, das mare magnum der Überlieferung mit dem Schleppnetz unserer Fragen zu durchziehen, wobei es durchaus legitim - aber letztlich nicht ausreichend - ist, die Gründe abzufischen, die sich gleichsam von selbst anbieten und von piscatores oder piscatrices mit ähnlichen Interessen auch schon aufgesucht worden sind ${ }^{1}$ : die Laichplätze

1 Aus der neueren einschlägigen Literatur seien in alphabetischer Reihenfolge hervorgehoben: Franco Alessio, La filosofia e le, artes mechanicae' nel secolo XII, in: Studi Medievali, Ser. 3, 6 (1965) 71-161; Guy H. Allard, Serge Lusignan (Hrsg.), Les arts mécaniques au Moyen Age (Cahiers d'études médiévales 7, Montréal, Paris 1982); Laetitia Boehm, Die artes mechanicae und artes liberales im Mittelalter. Die praktischen Künste zwischen illiterater Bildungstradition und schriftlicher Wissenschaftskultur, in: Festschrift für Eduard Hlawitschka zum 65. Geburtstag, hrsg. von Karl Rudolf Schnith, Roland Pauler (Münchner Hist. Stud. Abt. Mittelalt. Gesch. 5, Kallmünz 1993) 419-444; Laetitia Boebm, Technische Bildung von den Anfängen bis zur frühen Neuzeit, in: Geschichtsdenken - Bildungsgeschichte - Wissenschaftsorganisation. Ausgewählte Aufsätze von L. Boehm anläßlich ihres 65. Geburtstages, hrsg. von Gert Melville, Rainer A. Müller, Winfried Müller (Hist. Forsch. 56, Berlin 1996) 
der Enzyklopädisten, die Schatzkammern der Summisten, zu denen ich ausdrücklich auch Autoren wie Konrad von Megenberg mit seiner für die Handwerke so informativen „Ökonomik“ zähle², die Predigtliteratur - besonders die der Bettelorden mit ihren Sermones nulli parcentes - verdeutscht beispielsweise im „Buch der Rügen"3, die in den Bereich der Katechese gehörenden Kataloge der Tugenden und Laster, die Auslegungen der 10 Gebote und die Beichtspiegel ${ }^{4}$, die Totentanz-

447-492; Marshall Clagett, The Science of Mechanics in the Middle Ages (Publications in Medieval Science 4, Madison 1961); Claire Dolan (Hrsg.), Travail et travailleurs en Europe au Moyen Age et au début des temps modernes (Papers in Medieval Studies 13, Toronto 1991); Rainer S. Elkar (Hrsg.), Deutsches Handwerk in Spätmittelalter und Früher Neuzeit. Sozialgeschichte - Volkskunde - Literaturgeschichte (Göttinger Beiträge zur Wirtschafts- und Sozialgeschichte 9, Göttingen 1983); Helmut Flachenecker, Handwerkliche Lehre und Artes mechanicae, in: Europäische Technik im Mittelalter. 800 bis 1200. Tradition und Innovation. Ein Handbuch, hrsg. von Uta Lindgren (Berlin 1996) 493-502; Jacqueline Hamesse, Colette Muaraille-Samaran (Hrsg.), Le travail au Moyen Age. Une approche interdisciplinaire. Actes du Colloque international de Louvain-la-Neuve 21-23 mai 1987 (Université Catholique de Louvain. Publications de l'Institut d'Études Médiévales. Textes, Études, Congrés 10, Louvain-la-Neuve 1990); Pierre Jaccard, Histoire social du travail de l'Antiquité a nos jours (Paris 1960); Ria Jansen-Sieben (Hrsg.), Artes mechanicae en Europe médiévale, in middeleuwse Europa (Brüssel 1989); Friedrich Klemm, Die sieben mechanischen Künste des Mittelalters, in: Die BASF 12 (1962) 46-51; Hans Martin Klinkenberg, Homo faber mentalis. Über den Zusammenhang von Technik, Kunst, Organisation und Wissenschaft (Köln u.a. 1995) bes. 315-327; F. Krafft, (Art.) Artes mechanicae, in: Lex. d. MAs 1 (1977) 1063-1065; Pascale Lambrechts, Jean-Pierre Sossons (Hrsg.), Les Métiers au moyen âge. Aspects économiques et sociaux. Actes du colloque international de Louvain-la-Neuve. 7-9 octobre 1993 (Université Catholique de Louvain. Publications de l'Institut d'Études Médiévales. Textes, Études, Congrés 15, Louvain-la-Neuve 1994); George Ovitt, The Status of Mechanical Arts in Medieval Classifications of Learning, in: Viator 14 (1983) 89-105; Ortrun Riba, Das systematologische Defizit der Artesforschung. Überlegungen zur mittelalterlichen deutschen Fachliteratur, in: Arch. f. d. Studium der neueren Sprachen und Literaturen 229 (1992) 255276; Peter Sternagel, Die artes mechanicae im Mittelalter. Begriffs- und Bedeutungsgeschichte bis zum Ende des 13. Jahrhunderts (Münchner Hist. Stud. Abt. Mittelalt. Gesch. 2, Kallmünz 1966); Wolfgang Stürner, Technik und Kirche im Mittelalter, in: Technik und Religion, hrsg. von Ansgar Stöcklein, Mohammed Rassem (Düsseldorf 1990) 161-180; Elspeth Whitney, Paradise Restored. The Mechanical Arts from Antiquity through the Thirteenth Century (American Philosophical Society Transactions 8, part 1, Philadelphia 1990); Philippe Wolff, Frédéric Mauro, L'Age de l'Artisanat. Ve-XVIIIe Siècles (Histoire Général du Travail 2, Paris 1964).

2 Die Werke des Konrad von Megenberg. Ökonomik (Yconomica), hrsg. von Sabine Krüger, t. 1-3 (1973-1984) (MGH Staatsschr. d. sp. MAs 3, 5,1-3); außerordentlich hilfreich wegen der Register (z. B. s.v. mechanica ars), des Anmerkungsapparates und des Literaturverzeichnisses. 3 Zelina Zefarana, La predicazione ai laici dal secolo XIII al XV, in: Studi Medievali 3,24 (1983) 265-275; [sieben Autoren] (Art.) Predigt, in: Lex. d. MAs 7 (1995) 171-183; noch besserer bibliographischer Zugang über Hans-Jochen Schiewer, ,Die Schwarzwälder Predigten“. Entstehungs- und Überlieferungsgeschichte der Sonntags- und Heiligenpredigten (MTU 105, Tübingen 1996). Die im Druck befindlichen Faszikel 77 und 78 in der Reihe Typologie des sources du Moyen Age occidental (The Sermon), eingeleitet von B.M. Kienzle werden künftig als Hilfsmittel unentbehrlich sein. - Karin Schneider, ,Buch der Rügen', in: Die dtsch. Lit. d. MAs. Verfasserlexikon 1 (21978) 1096-1097.

${ }^{4}$ Zum Einstieg in diesen Sektor immer noch nützlich die Artikel Katechismus und Katechismusunterricht im Mittelalter und in der Neuzeit, in: RE f. prot. Theol. u. Kirche 10 (Leipzig 
darstellungen mit ihren Versen ${ }^{5}$, die Bücher zur ars moriendi ${ }^{6}$, die Osterspiele?, die Ständedidaxe und -satire ${ }^{8}$, die Schachallegorien', aber eben auch Reformtrak-

31901) 135-164 sowie (noch besser) Catéchèse und Catéchisme, in: Dict. de Théol. catholique 2,2 (Paris 21910) 1877-1968; außerdem Jobannes Geffcken, Der Bildercatechismus des 15.Jahrhunderts und die catechetischen Hauptstücke dieser Zeit bis auf Luther (Leipzig 1855); Peter Göbl, Geschichte der Katechese im Abendland vom Verfalle des Katechumenats bis zum Ende des Mittelalters (Kempten 1880); Peter Bablmann, Deutschlands katholische Katechismen bis zum Ende des sechzehnten Jahrhunderts (Münster 1894); Franz Falk, Drei Beichtbüchlein nach den zehn Geboten aus der Frühzeit der Buchdruckerkunst (Ref.gesch. St. u. Texte 2, Münster 1907); Egino Weidenhiller, Untersuchungen zur deutschsprachigen katechetischen Literatur des späten Mittelalters (MTU 10, München 1965); Volker Honemann, Johann Schotts „Spiegel christlicher Wallfahrt“ (1509): Ein Dekalogtraktat aus dem Umkreis des Straßburger christlichen Humanismus, in: Spätmittelalterliche geistliche Literatur in der Nationalsprache 2 (Analecta Cartusiana 106, Salzburg 1984) 28-102. Eine ,Geschichte der Katechese vom frühen Christentum bis zum späten Mittelalter' bietet an nicht gerade erwarteter Stelle an Karin Baumann, Aberglaube für Laien. Zur Problematik und Überlieferung spätmittelalterlicher Superstitionenkritik (Quellen u. Forschungen z. Europ. Ethnologie 6, Würzburg 1989) 11-122; im übrigen beruht ihre ganze Dissertation auf spätmittelalterlichen deutschen Dekalogtexten, vornehmlich zum 1. Gebot. - Zu den Beichtbüchern s. Jacques Le Goff, Métier et profession d'après les manuels de confesseurs au moyen âge, in: Beiträge zum Berufsbewußtsein des mittelalterlichen Menschen, hrsg. von Paul Wilpert (Miscellanea Medievalia 3, Berlin 1964) 44-60. - Zu dem nur handschriftlich überlieferten De decem preceptis Stephan Bodekers mit seiner ausführlichen Berücksichtigung der artes mechanicae s. Anm. 63.

${ }^{5}$ Auswahl von Texten und Abbildungen: Der Tanzende Tod. Mittelalterliche Totentänze, hrsg., eingel. u. übers. von Gert Kaiser (Frankfurt a.M. 1982); vgl. auch Wolfgang Stammler, Der Totentanz. Entstehung und Deutung (München 1948); Hellmut Rosenfeld, Der mittelalterliche Totentanz. Entstehung, Entwicklung, Bedeutung (Beih. z. AKG 3, Köln, Graz ${ }^{3}$ 1974); R. Hammerstein, Tanz und Musik des Todes (1980); Hartmut Freytag, (Art.) Revaler (Talliner) Totentanz, in: Verf.lex. (wie Anm. 3) 8 (1990) 2-6.

${ }^{6}$ Rainer Rudolf, Ars moriendi. Von der Kunst heilsamen Lebens und Sterbens (Forsch. z. Volkskunde 39, Köln 1957); ders., Die Ars-moriendi-Literatur des Mittelalters, in: Jb. f. Internat. Germanistik 3,1 (1971) 22-29; Claude Sutto (Hrsg.), Le sentiment de la mort au moyen âge. Études présentées au cinquième colloque de l'Institut d'études médiévales de l'Université de Montréal (Québec, Paris 1979).

7 Maximilian Rudolf Rudwin, Der Teufel in den deutschen geistlichen Spielen des Mittelalters und der Reformationszeit (Hesperia 6, Göttingen 1915), dort 30-37 u. 164 Auflistung von verschiedenen Berufen in den Spielen; Rolf Steinbach, Die deutschen Oster- und Passionsspiele des Mittelalters. Versuch einer Darstellung und Wesensbestimmung nebst einer Bibliographie zum geistlichen Spiel des Mittelalters (Köln, Wien 1970); s. auch Anm. 8 (Kulli) u. Anm. 26.

8 Grundlegend Wolfgang Heinemann, Zur Ständedidaxe in der deutschen Literatur des 13.15.Jahrhunderts, in: PUB 88 (1967) 1-90, 89 (1967) 290-403 und 92 (1970) 388-437; sehr nützlich Rolf Max Kulli, Die Ständesatire in den deutschen geistlichen Schauspielen des ausgehenden Mittelalters (Basler Studien 31, Bern 1966); Hubert Hoffmann, Die geistlichen Bindungen an Diesseits und Jenseits in der spätmittelalterlichen Didaktik. Vergleichende Untersuchungen zu Gesellschaft, Sittlichkeit und Glauben im „Schachzabelbuch“, im ${ }$ Ring " und in „Des Teufels Netz“ (Forschg. z. Oberrhein. Landesgesch. 22, Freiburg 1969); Ingmar ten Venne, Die Ständesatire im geistlichen Spiel des Spätmittelalters als literarischer Reflex mittelalterlichen ständischen Berufslebens, in: Jb. f. Gesch. d. Feudalismus 11 (1987) 127-140; ungedruckt blieb leider die Dissertation von Gerda Franz, Tugenden und Laster der Stände in der didaktischen Literatur des späten Mittelalters (Bonn 1957), dort 347-361: 
tate wie die Reformatio Sigismundi ${ }^{10}$, politiktheoretische Werke höchsten Ranges wie der Defensor pacis des Marsilius von Padua11, philosophisch-theologische Weltliteratur wie Dantes Komödie ${ }^{12}$, der Rosenroman und seine französischen, englischen und deutschen Nachahmungen bzw. Gegendichtungen ${ }^{13}$, weiter die Novellistik, Schwänke und Facetien ${ }^{14}$, Einblattdrucke ${ }^{15}$ usw. usw. Bei der näheren Musterung der Beute zeigt es sich dann, daß viele Erwartungen bestätigt werden -

V. Die Tugendlehre der bürgerlichen, bäuerlichen, handwerklichen ordines und spezifische Phänomene der Ständeethik. - Für den romanischen Raum: Hans Robert Jauss, La littérature didactique, allégorique et satirique (Grundriss der romanischen Literaturen des Mittelalters 6, Heidelberg 1970). Für England: Jill Mann, Chaucer and Medieval Estates Satire. The Literature of Social Classes and the ,General Prologue' to the ,Canterbury Tales' (Cambridge, New York 1973).

9 Zu des Jacobus de Cessolis Liber de ludo scaccorum bis ca. 1973 vgl. Thomas Kaeppeli O.P., Scriptores Ordinis Praedicatorum Medii Aevi 2 (Romae 1975) 311-318; danach Gerbard F. Schmidt, (Art.) Konrad von Ammenhausen, in: Verf.lex. (wie Anm. 3) 5 (1984) 136-139; Anton Schwob, (Art.) Schachzabelbücher, in: Verf.lex. 8 (1991) 589-592; Karl S. Kramer, Bauern, Handwerker und Bürger im Schachzabelbuch. Mittelalterliche Ständegliederung nach Jacobus de Cessolis (München 1995).

${ }^{10}$ Reformation Kaiser Siegmunds, hrsg. von Heinrich Koller (MGH Staatsschr. 6, Stuttgart 1964), die dort S. 383 im Wort- und Sachverzeichnis unter bantwerck, antwerck und bantwerksman angegebenen Stellen.

11 Marsilius von Padua, Defensor pacis, hrsg. von Richard Scholz (MGH, Fontes iur. Germ. antiq., Hannover 1932) 20-36 (Dict. 1, 5-7).

12 Dante Alighieri, Die göttliche Komödie, italienisch und deutsch, übers. von Hermann Gmelin (Stuttgart 21968), z. B. für Schneider: Parad. 15, 20f., 17, $101 \mathrm{f}$., 32, 140f.; für Schmiede: Parad. 1, 59f., 2, 127-129, 24, 102; für Köche: Infern. 21, 55-57; vgl. auch Guy $H$. Allard, Les arts mécaniques aux yeux de l'idéologie médiévale, in: G.H. Allard, S. Lusignan, (wie Anm. 1) 13-31, bes. 30; Pierre Antonetti, La vie quotidienne à Florence au temps de Dante (Paris 1979) bes. $155 \mathrm{ff}$.

13 Zum Rosenroman und seiner Wirkungsgeschichte vgl. Karl August Ott, Der Rosenroman (Erträge d. Forschg. 145, Darmstadt 1980) bes. 23-45 und 174-181; dort nicht berücksichtigt Adriaan Meijboom (Hrsg.), Die Pilgerfahrt des träumenden Mönchs (Rhein. Beitr. u. Hülfsbücher z. germ. Phil. u. Volkskde. 10, Bonn, Leipzig 1926) 170-173 (Dialog Arbeit - Pilger), 246-257 (Girichkeit - Pilger); vgl. auch Volker Honemann, (Art.) ,Pilgerfahrt des träumenden Mönchs', in: Verf.lex. 7 (1989) 683-687.

14 Georg Bollenbeck, Die Krise des Handwerks in spätmittelalterlichen Schwanktexten, in: Deutsches Handwerk, hrsg. von R. S. Elkar, (wie Anm. 1) 303-317 (berücksichtigt besonders den Eulenspiegel). - Nützliche Bibliographie zur Satire bei Helmut Arntzen, Satire in der deutschen Literaturgeschichte und Theorie 1: Vom 12. bis zum 17.Jahrhundert (Darmstadt 1989); für den englischen bzw. französischen Sprachraum etwa J. Mann, Chaucer and Medieval Estates Satire (Cambridge 1973); Charles Lenient, La Satire en France au moyen âge (Paris 1893); Heatber Arden, Fools' Plays. A Study of Satire in the Sottie (Cambridge 1980).

15 Schöne Beispiele bei Hellmut Rosenfeld, ,Die acht Schalkheiten', ,Die sechzehn Schalkhei-

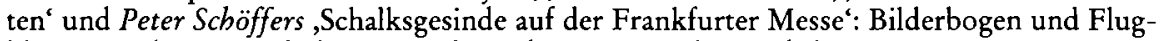
blätter aus dem Bereich des Fastnachtspieles, in: Gutenberg-Jahrb. 56 (1981) 193-206. - Das Blatt mit den acht Schalkheiten ist auch wiedergegeben bei Harry Kühnel, Alltag im Spätmittelalter (Graz u. a. 21985) 333, Abb. 407. - Zu allen erwähnten Genera in der europäischen und deutschen Literatur s. auch Willy Erzgräber, Europäisches Spätmittelalter (Heidelberg, Wiesbaden 21978) und Thomas Cramer, Geschichte der deutschen Literatur im späten Mittelalter (dtv 4553, München 1990). 
etwa durch Vincent von Beauvais ${ }^{16}$, Konrad von Megenberg ${ }^{17}$, Berthold von Regensburg ${ }^{18}$ oder durch den anonymen Verfasser von „Des Teufels Netz"19 aber ebenso viele auch enttäuscht werden - so in den Christenspiegeln eines Dietrich Kolde ${ }^{20}$ oder eines Jakob von Gruitrode ${ }^{21}$, in den Sündenspiegeln eines Martin von Amberg ${ }^{22}$, bei den Totentänzen ${ }^{23}$, im Narrenschiff des Sebastian Brant ${ }^{24}$, ja sogar weitgehend im Oeuvre der Handwerkerliteraten Hans Folz, Rosenplüt

16 Vincentius Bellovacensis, Speculum doctrinale (Duai 1624, ND Graz 1965) 993-1072, L. $\mathrm{XI}$ : De arte mechanica et speciebus eius; vgl. Serge Lusignan, Les arts mécaniques dans le Speculum Doctrinale de Vincent de Beauvais, in: Allard, Lusignan, (wie Anm. 1) 33-48.

17 Wie Anm. 2.

$18 \mathrm{Vgl}$. Hans Joachim Schmidt, Arbeit und soziale Ordnung. Zur Wertung ständischer Lebensweise bei Berthold von Regensburg, in: AKG 71 (1989) 261-296 und die dort verwertete Literatur. - Zentraler, aber nicht einziger Text ist bekanntlich die Zehnte Predigt. Von den zeben koeren der engele unde der kristenbeit, in: Bertbold von Regensburg, Vollständige Ausgabe seiner Predigten mit Anmerkungen von Franz Pfeiffer. Mit einem Vorwort von Kurt Rub, 1 (Berlin 1965, zuerst Wien 1862) 140-156.

19 Des Teufels Netz. Satirisch-didaktisches Gedicht, hrsg. von Karl August Barack (Bibl. d. Litt. Ver. Stuttg. 70, Stuttgart 1863); vgl. Anke Ehlers, Des Teufels Netz. Untersuchung zum Gattungsproblem (Stuttgart u.a. 1973) auch sehr nützlich für den Vergleich zu den Osterspielen usw. Mehr als 60 handwerkliche Berufe und Stände werden in "Des Teufels Netz“ aufs Korn genommen.

20 Kritische Ausgabe von Der Kerstenen Spiegel: Der Christenspiegel des Dietrich Kolde von Münster. Kritisch hrsg. von Clemens Drees (Franzisk. Forschg. 9, Werl 1954); vgl. mit reichen Literaturangaben Benjamin de Troeyer, (Art.) Kolde (Colde, Coelde), Dietrich, von Osnabrück, von Münster, in: Verf.lex. (wie Anm. 3) 5 (1984) 19-26.

21 Preben Bange, De Specula omnis status bumanae vitae van Jacobus van Gruitrode: Vijftiende eeuwse Standenspiegels, in: Ons Geestelijk Erf 57 (1983) 134-179. Jacobs Speculum aureum anime peccatricis ist 1488 in Bésançon zusammen mit dem Speculum Arévalos gedruckt worden; s. unten Anhang 1, B, a, Nr. 18; heute zu benutzende Ausgabe in: D. Dionysii Cartusiani opera omnia 42 (Tournai 1913) 651-815; vgl. auch Kurt Ruh, (Art.), Der goldene Spiegel der armen sündigen Seele', in: Verf.lex. 3 (1981) $91 \mathrm{f}$.

22 Martin von Amberg, Der Gewissensspiegel, hrsg. von Stanley Norman Werbow (Texte d. sp. MAs u. d. fr. Neuzeit = T. sp. MA 7, Berlin 1958) beschränkt sich (64f.) auf Hinweise zur Feiertagsruhe und zum Geiz; zu Autor und Werk vgl. Stanley N. Werbow, (Art.) Martin von Amberg, in: Verf.lex. 6 (1985) 145-149. - Auch Heinrich von Langenstein, Erchantnuzz der sund, hrsg. von Rainer Rudolf (T. sp. MA 22, Berlin 1969) enthält keine für die Handwerkereinschätzung brauchbaren Hinweise. Mehr Aufschluß verspricht ein nur handschriftlich zugängliches Beichthandbuch, das Johann von Freiburg aus seiner summa confessorum für simpliciores et minus expertos confessores zusammengestellt hatte mit besonderer Zuwendung u. a. ad mercatores et burgenses (XI), ad artifices et mechanicos (XII), ad rusticos et agricolas (XIII) und ad laboratores; vgl. Le Goff, (wie Anm. 4) 57.

23 Wie Anm. 5.

${ }^{24} \mathrm{Zu}$ den Editionen und zur Sekundärliteratur vgl. Thomas Wilhelmi, Sebastian Brant Bibliographie (Arb. z. mittl. Deutschen Lit. u. Spr. 18,3, Bern u. a. 1990); Joachim Knape, Dieter Wuttke (Hrsg.), Sebastian-Brant-Bibliographie: Forschungsliteratur von 1800 bis 1985 (Tübingen 1990). In der unmittelbaren Nachfolge von Brant wurde 1504 geschrieben: Das Windschiff aus Schlaraffenland, hrsg. von Erich Kleinschmidt (Bibliotheca Germanica 20, Bern, München 1977), das aber nur einzelne Stände und Berufe (Apotheker, Kaufleute, Drucker, Hebammen) vorführt, für eine systematische Handwerkerkritik also wenig hilfreich ist. 
und Hans Sachs ${ }^{25}$. Von Historikern weniger wahrgenommene Literatur wie etwa das Innsbrucker (aber aus Mitteldeutschland stammende) sowie das norddeutsche Redentiner Osterspiel mit ihren Erwähnungen von Bierschenken, Bäckern, Fleischern, Schustern, Sporern, Feilenhauern, Brettschneidern, Dielenmachern, Müllern, Badern, Schmieden, Wollkämmern, Bürstenbindern und anderen Handwerkern erweisen sich hingegen als positiv überraschende Fundgruben ${ }^{26}$. Die Gründe für die hier im Bereich der Didaxe genannten Bestätigungen oder Enttäuschungen von Erwartungen sowie für die erfreulichen Überraschungen liegen wohl u.a. in den seit dem 13.Jahrhundert weitgehend nebeneinanderherlaufenden Intentionsund Adressatensträngen, weil man nämlich einmal ausging von Tugenden, Lastern und Narreteien, die mehr oder weniger alle Christenmenschen betrafen, und weil man zum anderen nach Ständen und Berufen differenzierte, also bestimmte soziale Zielgruppen ansprechen und erreichen wollte.

Als ein Schuster, der bei seinem Leisten zu bleiben hat, möchte ich, dem für das Kolloquium Wünschbaren zum Trotz, keinen konzentrierten Ertrag sorgfältig und systematisch durchgeführter Quellenrecherchen zur Einschätzung der Handwerker oder der artes mechanicae anbieten, sondern für die verstärkte

25 Vgl. Johannes Janota, Die Rolle des Handwerks und der Handwerker in den Werken des Nürnberger Handwerksliteraten Hans Folz, in: Elkar, (wie Anm. 1) 265-282 (auch mit Hinweisen auf Rosenplüt, Hans Sachs, Fastnachtspiele usw.). Jörn Reichel, Handwerk und Arbeit im literarischen Werk des Nürnbergers Hans Rosenplüt, in: Elkar, (wie Anm. 1) 245263. Hans Sachs, Eygentliche Beschreibung Aller Stände auff Erden (Frankfurt a.M. 1568) heute leicht einzusehen als Faksimilereproduktion (Hanau 1966) oder unter dem Titel Jost Amman, Das Ständebuch. 133 Holzschnitte mit Versen von Hans Sachs und Hartmann Schopper, hrsg. von Manfred Lemmer (Frankfurt a.M. 101988) - widmet zwar bei 114 vorgestellten Ständen gegenüber sechs geistlichen, vier hohen weltlichen und vier gehobenen bürgerlichen Positionen (Arzt, Apotheker, Astronom und Prokurator) sowie vier Narrentypen den 97 genannten Handwerkern die größte Aufmerksamkeit, jedoch sind seine knappen Zeilen zu plakativ für eine handwerkstheoretische Auswertung. - Auch Ferdinand Seibt, Vom Lob der Handarbeit, in: Vom Elend der Handarbeit. Probleme historischer Unterschichtenforschung, hrsg. von Hans Mommsen, Winfried Schulze (Geschichte und Gesellschaft 24, Stuttgart 1981) 158-181, hier 179 stellte fest, daß das europäische Handwerk um 1500 nicht einmal in seinem eigenen Meistergesang sein Lob gesungen hat, jedoch in Stichen und Radierungen, oft mit verklärenden Versen, mit Nachdruck seine Selbstdarstellung betrieb. Für die spätmittelalterliche deutsche Geschichtsschreibung kommt zu einem ganz ähnlichen Ergebnis - „Auf die Bewertung der weltlichen Handwerker schlägt die positive Beurteilung von Handwerk und Technik im allgemeinen nicht durch ${ }^{\text {" }}$ - Rolf Sprandel, Handwerklich-technischer Aufschwung im Spätmittelalter: Seine Reflexe in der zeitgenössischen Historiographie, in: Handwerk und Sachkultur im Spätmittelalter (Veröff. d. Inst. f. mittelalterl. Realienkunde Österreichs 11, Wien 1988) 9-31, hier 31.

26 Das Innsbrucker Osterspiel. Das Osterspiel von Muri. Mittelhochdeutsch und neuhochdeutsch, hrsg., übersetzt, mit Anmerkungen und einem Nachwort versehen von Rudolf Meier (Stuttgart 1962) bes. 34-41; weitere Ausgaben sowie Literatur bei Bernd Neumann, (Art.), Innsbrucker (thüringisches) Osterspiel', in: Verf.lex. (wie Anm. 3) 4 (1982) 400-403. Das Redentiner Osterspiel. Mittelniederdeutsch und Neuhochdeutsch, übers. u. komm. von Brigitta Schottmann (Recl. UB 9744-47, Stuttgart 1975) bes. 106-111; weitere Ausgaben und Literatur bei Hans Jürgen Linke, (Art.) Redentiner Osterspiel, in: Verf.lex. 7 (1989) 10651069. 
Wahrnehmung und Nutzung eines Textes werben, auf den ich aus allgemeineren sozialtheoretischen und verfasserorientierten Interessen gestoßen bin: auf das Speculum vite humane des Rodericus Zamorensis. Wer mehr erwartet haben sollte, mag in den relativ reichen bibliographischen Hinweisen im Anmerkungsapparat ein Zeichen guten Willens sehen.

Geschrieben oder doch vollendet ist das Speculum in Rom im Jahre 1467, und zwar höchstwahrscheinlich vor dem 30 . Oktober ${ }^{27}$. Eine frühe Handschrift bewahrt dort die Biblioteca Angelica auf, mehr als ein weiteres Dutzend sollen sich in der Vaticana, in Metz, Nürnberg, Leipzig, München, Breslau, Wien usw. befinden. Schon sehr bald - zumal für römische Verhältnisse - hat sich der Buchdruck des Speculums angenommen und zu seiner raschen, weiten und langandauernden Verbreitung beigetragen: erster Druck also in Rom bei Sweynheim und Pannartz 1468; eben dort - aber noch ohne Zuweisungsmöglichkeit an einen bestimmten Drucker (wahrscheinlich bei G. Lauer) 1470; der dritte bei Zainer in Augsburg 1471; mindestens 15 weitere Drucke bis 1488 in Italien, Deutschland, Frankreich und Piemont. Neben diesen Drucken des lateinischen Textes fallen noch in die Inkunabelzeit vier Drucke der deutschen, durch Heinrich Steinhöwel geleisteten Übersetzung, 1475, 1479 und 1488 in Augsburg, vier französische Übersetzungen in Lyon, Straßburg und Toulouse zwischen 1477 und 1480 gedruckt und eine Traducción española (ins Kastilische), 1491 bei Pablo Hurus in Zaragoza in zwei Auflagen. Mindestens zehnmal ist das Werk dann noch im 16. Jahrhundert - darunter in einer Straßburger, von Sebastian Brant mit einer Elegia versehenen, Bearbeitung von 1507 - und zwischen 1606 und 1683 ebenfalls noch achtmal aufgelegt worden. Es handelt sich mithin um ein Werk, das im ausgehenden Mittelalter und in der frühen Neuzeit im west-, süd- und mitteleuropäischen Raum seine Beachtung, überwiegend und auf die Dauer freilich nur bei einer lateinkundigen Leserschaft, gefunden hat und insofern mir eine gewisse Berechtigung verleiht, es im Rahmen dieser überregional ausgerichteten Tagung vorzustellen oder in Erinnerung zu bringen ${ }^{28}$.

Bevor ich auf Aufbau und Gliederung, Quellen und Vorlagen des Speculum vite bumane und sodann auf die den artes mechanicae gewidmeten Kapitel eingehe,

27 Die Abfassungszeit ergibt sich aus dem in diesem Jahr beendeten Episkopat von Zamora und der am 30. Oktober 1467 erfolgten Übernahme der Diözese Calahorra; zu Calahorra vgl. Laboa, (wie Anm. 29) 329. Rodrigo nennt sich im Widmungsteil lediglich Episcopus zamorensis, während der erste Druck von 1468 im Titel, der der Widmung handschriftlich (!) vorangestellt wurde, formuliert: editus a Rodorico episcopo Zamorensi, postea Calagurritano bzw. calagorritano; vgl. Frederick R. Goff, The Earliest Instance of Printing on Vellum in an Italian Book. With two figures, in: Gutenberg Jahrb. (1966) 80-85. A révalo, der sich mit einer Oratio ... ad ... Paulum II ... gratias agens de traslatione (!) ad ecclesiam calagurritanam beim Papst bedankte - vgl. Laboa, (wie eben) 329 mit Hinweis auf Corpus Christi College, Ms. 166, f. 150v-151v-, hätte bei seiner Widmung an Paul II. wohl kaum seine ,Beförderung verschwiegen. Trame, (wie Anm. 29) 167 hielt noch eine Abfassung anfangs des Jahres 1468 für möglich.

${ }^{28} \mathrm{Zu}$ den Handschriften und Drucken vgl. unten Anhang 1. 
scheinen mir einige Bemerkungen zum Autor und seiner literarischen Gesamtproduktion nützlich zu sein ${ }^{29}$.

In den Drucken des Speculum wird der Verfasser in der Regel als Rodoricus/Rodericus Zamorensis oder Rodoricus episcopus Zamorensis bezeichnet, er war also zum Zeitpunkt der Niederschrift Bischof der im nordwestlichen Spanien - etwa auf der Höhe von Valladolid und circa $160 \mathrm{~km}$ nördlich von Salamanca - liegenden Diözese Zamora, freilich nur dem Titel und den Einkünften nach, denn sein Wohnsitz und Arbeitsplatz war seit dem Beginn des Pontifikats Pauls II. die Engelsburg, die jener Papst ihm anvertraut hatte. Sein voller Name war Rodrigo Sánchez de Arévalo. Geboren 1404, zehnjähriges beachtenswert breites Studium in Salamanca: Bakkalaureus des weltlichen Rechts, des geistlichen Rechts, der Theologie und der Artes liberales. Zwischen 1433 und 1439 Mitglied der kastilischen Delegation auf dem Basler Konzil ${ }^{30}$. In diesem Zusammenhang Adressat eines wichtigen konzilstheoretischen Schreibens des Nikolaus von Kues (1442) ${ }^{31}$, aber schon hier scharfer Verfechter papalistischer Positionen und engagierter Streiter gegen die kurfürstliche Neutralität. In den 40er und 50er Jahren mehrfache Verwendung im diplomatischen Dienst seiner Könige, aber auch für Nikolaus V. und Calixt III. bei gleichzeitigem Aufstieg in der kirchlichen Hierarchie zu Burgos; 1457 Bischof von Oviedo, sodann 1465-1467 von Zamora, 1467-1469 von Calahorra und schließlich ab 6. Oktober 1469 von Palencia. Immer länger währende Aufenthalte in Rom, wo er schon 1448 Cubicularius und unter Calixt Referendarius an der Kurie wurde. Unmittelbar nach dem Amtsantritt Papst Pauls II. im Spätsommer 1464 Ernennung zum Kastellan der Engelsburg. 4. Oktober 1470 Tod. Grab in der spanischen Kirche Santiago an der Piazza Navona.

29 Ich stütze mich im folgenden besonders auf Teodoro Toni, Don Rodrigo Sánchez de Arévalo, 1404-1470. Su personalidád y actividades. El tratado „De pace et bello“, in: Annuario de Historia del Derecho Español 12 (1935) 97-360; Richard H. Trame, Rodrigo Sánchez de Arévalo 1404-1470. Spanish Diplomat and Champion of the Papacy (The Catholic University of America. Studies in Medieval History, NS 15, Washington D.C. 1958); Juan Maria Laboa, Rodrigo Sánchez de Arévalo, Alcaide de Sant' Angelo (Publicaciones de la Fundación Universitaria Española, Monografias 8, Madrid 1973); Wolfram Benziger, Zur Theorie von Krieg und Frieden in der italienischen Renaissance. Die Disputatio de pace et bello zwischen Bartolomeo Platina und Rodrigo Sánchez de Arévalo und andere anläßlich der Pax Paolina (Rom 1468) entstandene Schriften. Mit Edition und Übersetzung (Europäische Hochschulschr. III, 702, Frankfurt a.M. u. a. 1996) bes. T. 1, 24ff. - Kurzinformationen u. a. bei $A$. Lambert, Arévalo, Rodrigo Sánchez de, in: Dict. d. Hist. et de Géogr. Eccl. 3 (1924) 16571661 (die beste!); Antonio Garcia y Garcia, Sánchez de Arévalo, Rodrigo, in: Diccionario de Historia Ecclesiástica de España 4 (Madrid 1975) 2169f.; Saturnio López Santidrián, Sánchez de Arévalo (Rodrigo), in: Dict. de Spiritualité 14 (1990) 301-303; Georg Kreuzer, Sánchez de Arévalo Rodrigo, in: Biographisch-bibliographisches Kirchenlexikon 8 (1994) 1192-1194; Ludwig Vones, Sánchez de Arévalo, Rodrigo, in: Lex. MA 7 (1995) 1351.

$30 \mathrm{Vgl}$. Johannes Helmrath, Das Basler Konzil 1431-1449. Forschungsstand und Probleme (Köln. Hist. Abh. 32, Köln, Wien 1987) bes. 247; Benziger, (wie Anm. 29) 25.

31 Hinweise auf Handschriften, Drucke, Erwähnungen usw. durch Erich Meuthen (Hrsg.), Acta Cusana. Quellen zur Lebensgeschichte des Nikolaus von Kues 1,2 (Hamburg 1983) $372 f .$, Nr. 516. 
Die Kardinäle Bessarion und Marcus Barbo verfaßten den Text seines heute in Santa Maria de Montserrat in Rom befindlichen Epitaphs ${ }^{32}$. In summa also: ein Spanier gehobener Herkunft, breiter Bildung mit weitem Erfahrungshorizont und angesehener, aber nicht erstrangiger Position in Rom und im Kreis der geistigen Elite seiner Zeit.

Arévalo hat außer Predigten und Briefen 28, in der Mehrzahl recht umfangreiche Werke geschrieben, von denen nur vier - sein Liber de monarchia orbis ${ }^{33}$, das Speculum vite bumane ${ }^{34}$, seine Historia Hispanica ${ }^{35}$ sowie sein Trauer- und Trostbrief über die Eroberung von Euböa ${ }^{36}$ in frühen Drucken und weitere sechs in neueren Editionen vorliegen ${ }^{37}$. Seine Interessenfelder waren 1. Spanische Landeskunde, Geschichte und Politik; 2. aktuelle Ekklesiologie (mit papalistischer Tendenz); 3. tagespolitische und tagestheologische Probleme; 4. spezielle und allgemeine Didaxe, wozu ich seinen Traktat über die Kindererziehung, seinen spanischen Fürstenspiegel ${ }^{38}$ und das Speculum vite bumane rechnen würde. Im deutschsprachigen Raum des ausgehenden 15.Jahrhunderts war wohl lediglich sein Speculum den Gebildeten bekannt. Johannes Trithemius jedenfalls hielt in seinen De scriptoribus ecclesiasticis (1494) fest: Rodericus episcopus Samorensis vir in

32 Text der Inschrift bei Benziger, (wie Anm. 29) 25 mit weiteren Hinweisen.

33 Liber de monarchia orbis et de differentia cuiusvis humani principatus tam imperialis quam regalis et de antiquitate et iustitia utriusque (1467) (Rom 1521).

34 Vgl. unten Anhang 1.

35 Historia Hispanica (1469-70) (Rom 1470); wieder abgedruckt in: Hispaniae illustratae ... scriptores varii 1 (Frankfurt, Andreas Schott, 1603) 121-226; vgl. Norbert Kersken, Geschichtsschreibung im Europa der „nationes“. Nationalgeschichtliche Gesamtdarstellungen im Mittelalter (Münster. Hist. Forschg. 18, Köln u. a. 1995) bes. 17-19 u. 753 („Beginn der Druckgeschichte nationalgeschichtlicher Gesamtdarstellungen").

${ }^{36}$ Epistula lugubris et moesta simul et consulatoria de infelice expugnatione insulae Euboyae dictae Nigropontis (1470) (Rom 1470, Köln 1470/71, Mainz o.J.).

37 1. De arte, disciplina et modo alendi et erudiendi filios, pueros et iuvenes (1453), hrsg. von Hayward Keniston, A Fifteenth-Century Treatise on Education by Bishop Rodericus Zamorensis (1453), in: Bulletin Hispanique 32 (1930) 193-217. - 2. Suma de la Politica (1454-1455), hrsg. von Mario Penna, Rodrigo de Arévalo, Suma de la Politica, in: Biblioteca de autores españoles 116 (Madrid 1959) 249-309. - 3. Vergel de los principes (1456-1457), hrsg. von $F$ de Ubagón (Madrid 1900); besser: Mario Penna, in: wie Nr. 2, 311-341. -4. Oratio ad Pium secundum super recuperatione civitatis de Gibraltar a rege Castellae (1462), hrsg. von Horatio Santiago-Otero, Rodrigo Sánchez de Arévalo. Discurso a Pio II con motivo de la conquista de Gibraltar (1462), in: Revista Española de Teologia 37 (1977) 153-158. - 5. Libellus de libera et irrefrigabile auctoritate Romani pontificis (1464-1467), hrsg. von Antonio Garcia y Garcia, Un opusculo inédito de Rodrigo Sánchez de Arévalo: De libera ..., in: Salamanticensis 4 (1957) 474-502. - (De pace et bello) Reverendus pater Rhodericus episcopus Calaguritanus Hispanus castri Sancti Angeli de urbe castellanus: De commendatione belli. De difficultate humanae quietis, quem pacem vocant, et quae sit vera pax, in: Altercatio sive disputatio de pace et bello inter reverendum patrem Rhodoricum episcopum Calaguritanum Hispanum et Bartholomeum Platinam (1468), hrsg. von Wolfram Benziger (wie Anm. 29), dort im Editionsteil 22-89, deutsch im Übersetzungsteil 20-72. Überholt ist damit der unzulängliche Druck bei Tommaso Agostino Vairani, Cremonensium Monumenta Romae extantia I (Rom 1778) 67-106.

38 Vgl. Anm. 37, Nrr. 1 und 3. 
divinis scripturis studiosus et eruditus, et secularium literarum non ignarus, ingenio praestans et clarus eloquio. Scripsit ingenii sui non contemnandae auctoritatis opuscula, quibus memoriam sui nominis posteritati commendavit. De quibus ego vidi adbuc tantum volumen vnum quod praenotavit: Speculum humane vitae... Cetera non vidi... ${ }^{39}$.

Der Kastellan der Engelsburg gibt in seinem Dedikationsvorwort an Paul II. selbst Informationen über die Intention sowie Aufbau und Gliederung seines Speculum, in dem übrigens - das sei hier schon betont - die den artes mechanicae gewidmeten Kapitel nur etwa ein Zehntel der im Augsburger Druck von 1471 insgesamt benötigten 254 Textseiten füllen ${ }^{40}$.

Es sei ihm in den Sinn gekommen, wie viele und verschiedene studia, artes, officia und vivendi genera es gebe und daß eine vernünftige Entscheidung nur möglich sei, wenn man die dulcia et amara, die commoda et incommoda diversorum statuum kenne. Diese in einem klaren Spiegel - in limpidissimo speculo - vorzuführen, sei sein Anliegen. Gemäß der Papst Gelasius unterstellten Zwei-Lebensarten-Lehre ${ }^{41}$ (genera vivendi) befasse er sich im ersten Buch mit den weltlichen Ständen von den Königen und Fürsten bis hinab zu den Ochsentreibern (bubulcos) und entsprechend im zweiten Buch, beginnend mit dem Papst, mit den geistlichen Ständen, wobei er noch einmal zwei Hauptgruppen - den status ecclesiasticus und den status regularis sive monasticus - unterscheidet ${ }^{42}$.

39 Im Druck von 1613 (Hanau) 369; vgl. Anhang 1, C, a, Nr. 12.

40 Ich zitiere im folgenden nach dem Augsburger Druck vom 11. Jan. 1471 (vgl. Anhang 1, B, a Nr. 3), dessen Blattzählung freilich nachträglich mit der Hand eingetragen ist, und gebe dazu in Klammern die entsprechende Blattzählung der deutschen, in Augsburg bei Zainer erschienenen Fassung von 1475 (vgl. Anhang 1, B, b Nr. 1).

41 2r: ... teste Gelasio papa, duo sunt vite genera, quibus orbis principaliter regitur, ebenso 3v; in dem bekannten Gelasiuszitat steht nichts von vite genera. - Zur Titelgebung vgl. Herbert Grabes, Speculum, Mirror und Looking-Glass. Kontinuität und Originalität des Spiegelmetapher in den Buchtiteln des Mittelalters und der englischen Literatur des 15. bis 17. Jahrhunderts (Buchreihe der Anglia 16, Tübingen 1973), wo (S. 275) der Verfasser eines Speculum bumanae vite als "unsicher; evtl. Rodericus Zamorensis (Sancius de Arevalo) “ angegeben wird, was aber eine irrige Vermutung ist (s. unten Anlage 1, A, a); eine „Blütenlese“ von Speculum/ Spiegel-Titeln schon bei Paul Lebmann, Mittelalterliche Buchtitel, in: ders., Erforschung des Mittelalters. Ausgewählte Abhandlungen und Aufsätze 5 (Stuttgart 1962) 1-99, bes. 73-84. Eine Liste von 38 ,Spiegel'-Titeln aus der Inkunabelzeit in der kgl. Bibliothek zu Den Haagdarunter auch als Nr. 31 Sánchez de Arévalo - hat zusammengestellt Preben Bange, Vijftiende eeuwse speculum - Literatuur in de Nederlanden: Een Verkenning van Terrein en Materiaal, in: Arch. v. d. Geschiedenis v. d. Katholieke Kerk in Nederland 22 (1980) 122-153, hier 141-153. Für 1999 ist angekündigt: Gunbild Roth, ,Speculum-/Spiegelliteratur' - Zu Gattungsfrage, Textsorten und Einzelwerken. Versuch eines Überblicks. Mit einem Anhang: ,Spiegel'-Texte. Eine Auswahl in chronologischer Reihenfolge (Forschungsberichte zur germanistischen Mediävistik = Jhb. f. Internat. Germanistik, Beih.-Reihe C: Forschungsberichte 5/2). - Arévalos Buchtitel ist von einem Urenkel Kaiser Maximilians übernommen worden; vgl. Speculum vitae humanae. Ein Drama von Erzherzog Ferdinand II. von Tirol 1584. Nebst einer Einleitung in das Drama des XVI.Jahrhunderts, hrsg. von Jacob Minor (Neudr. dtsch. Lit.werke d. XVI. u. XVII. Jhs. 79 u. 80, Halle 1889).

$421 \mathrm{v}-2 \mathrm{v}$. 
Die eigentliche prefatio ist mindestens so interessant, wenngleich sie nicht in alle Drucke und speziell nicht in die deutsche Übersetzung aufgenommen wurde ${ }^{43}$. Arévalo erläutert hier sein methodisches Vorgehen, sein rollenverteiltes dialogisches Abwägen der Für und Wider der einzelnen Berufe in Form einer (nicht immer durchgehaltenen) altercatio, autobiographisch und vom Grundansatz her durchaus glaubwürdig: Nach dem frühen Tod des Vaters sei es zu scharfen Auseinandersetzungen zwischen seiner Mutter auf der einen Seite und den Verwandten und Freunden des Elternhauses auf der anderen Seite darüber gekommen, was denn der Junge einmal werden sollte. Während die fromme Mutter (pia mater) einen geistlichen Werdegang wünschte und deshalb eine Ausbildung in den spirituales scientiae vorsah, wollten die Verwandten, daß Rodrigo in die Fußstapfen seines als Stadtoberhaupt angesehenen Vaters trete, Haus und Familie aufrechterhalte und sich somit ad seculares sciencias wende. Die Mutter mußte nachgeben, konnte aber immerhin erreichen, daß ihr Sohn während seines zehnjährigen Studiums in Salamanca über die iusticia bumana die iusticia divina nicht vergaß, also weltliches und kirchliches Recht studierte und außerdem der philosophia moralis sein spezielles Interesse zuwandte. Nach Abschluß des Studiums hatte sich der junge Mann nun endlich für einen modus future vite zu entscheiden, und es kam erneut zu einer altercatio, einem Streitgespräch zwischen seiner Mutter und den Verwandten super cunctas vite humane artes et vivendi modos mit dem Ergebnis, daß Arévalo - vielleicht auch mit Rücksicht auf sein corpusculum ${ }^{44}$ - den status spiritualis wählte.

Im ersten, die weltlichen Stände thematisierenden (und hier allein interessierenden) Buch werden die Pro-Argumente den Verwandten und Freunden, die Contra-Bedenken der Mutter in den Mund gelegt. Bekanntlich ist die Dialogform in der vergleichbaren Literatur des Mittelalters nichts Ungewöhnliches, doch sei darauf hingewiesen, daß unser Spanier sich dieser Methode besonders gern bediente: so schon in seiner ersten Abhandlung, dem Dialogus de remediis schismatis von $1440 / 42^{45}$ und in der gemeinsam mit Platina verfaßten Altercatio de pace et

$432 v-4 r$.

$44 \mathrm{Im}$ Widmungsvorwort $1 \mathrm{r}$ und in der Praefatio 4r. - Einen interessanten Vorläufer in der Geschichte der mittelalterlichen Berufswahl hatte Arévalo in Ambrosius von Siena (12001286), dessen Kult zu seinen Lebzeiten (1443) approbiert wurde. Der Vater des Ambrosius soll für den Knaben zwei Bücher angefertigt haben lassen, das eine cum nonnullis secularium bominum imagines, das andere, in quo religiosorum imagines pictae erant. Das Buch mit den Abbildungen Weltlicher habe er verschmäht, aber gerne und mit Freude das andere angesehen, womit der Lebensweg entschieden war; vgl. Vita B. Ambrosii Senensis c. 1, 5 u. 6, in: Acta Sanctorum Martii T. 3 (Antwerpen 1670) 183; Hinweis mit ungenauer Quellenangabe auch schon bei Shulamith Shahar, Kindheit im Mittelalter (München, Zürich 1991) 135.

45 Außer der von Laboa, (wie Anm. 29) 419 genannten Hs. Vat. lat. 4002 lag mir noch das besser lesbare Ms. lat. fol. 505, 13r-51 v der Staatsbibliothek Berlin vor, wo aber die erste Lage fehlt; vgl. auch Paul Oskar Kristeller, Iter Italicum III (London, Leiden 1983) 482. Partner in diesem Dialog ist ein Theodericus, der wahrscheinlich identisch ist mit dem Aschaffenburger Kanoniker Dietrich Ebrach; vgl. Trame, (wie Anm. 29) 34, Anm. 32. 
bello von $1468^{46}$. Im übrigen hat er sich bei der Betrachtung der beiden Seiten einer Münze nachweislich angelehnt an Petrarcas De remediis utriusque fortu$n a e^{47}$. Er verweist auf ihn, bzw. auf den poeta laureatus, im ersten Buch achtmal. Wer sind die übrigen Autoren oder Autoritäten, auf die er sich stützt oder die er von seinen Verwandten bzw. seiner Mutter nennen läßt? Aus dem Alten Testament vornehmlich die Propheten Jeremia und Jesaja, Salomon, Hiob, David; aus dem Neuen Testament fast ausschließlich der Apostel Paulus. Aus der griechischen Antike einmal Homer, dreimal Plato (Staat), mindestens 63mal (wenn ich richtig gezählt habe) Aristoteles, und zwar nicht nur seine Politik, sondern auch seine Ethik und Rhetorik sowie seinen Liber de animalibus. Aus der römischen Antike Cicero (24mal), Seneca (18mal), Boethius (fünfmal), Cato (fünfmal), ferner Plutarch, Juvenal, Apuleius, Ovid, Quintilian, Valerius, Vegetius und Virgil ( $\mathrm{Ge}$ orgica zweimal). Unter den Kirchenvätern steht Augustin mit 40 Verweisen an erster Stelle, gefolgt von Gregor d.Gr. (14mal), Hieronymus (12mal), Ambrosius und Chrysostomos (je viermal) sowie Cassiodor, Gelasius, Laktanz, Cyprian und Benedikt. Isidor von Sevilla wird neunmal genannt. Aus der arabischen Welt wird achtmal Alfarabius (d.i. Al-Farabi) ${ }^{48}$ erwähnt, wobei ich es für wahrscheinlich halte, daß Arévalo den 980 in Damaskus gestorbenen Philosophen nicht unmittelbar gelesen hat, sondern ihn aus der als Vorlage verschwiegenen, in den Jahren 1140-1150 entstandenen De divisione philosophiae seines Landsmanns Dominicus Gundissalinus kannte ${ }^{49}$. Verhältnismäßig schwach ist die lateinische Literatur seit

46 Vgl. Anm. 37, Nr. 6.

47 Francesco Petrarca, Opera omnia 1 (Basel 1554) 1-254; deutsch mit Vorrede von Sebastian Brant und Widmung von Georg Spalatin von 1521: Franciscus Petrarcha, Von der Artzney bayder Glück, des guten vnd widerwertigen (Augsburg 1532), hrsg. und kommentiert von Manfred Lemmer (Leipzig 1984); weiterer, mit einem Vorwort von M. Schneider versehenen ND (Die bibliophilen Taschenbücher 385, Dortmund 1983); Francesco Petrarca, Heilmittel gegen Glück und Unglück. De remediis utriusque fortunae. Lateinisch-deutsche Ausgabe übersetzt und kommentiert von Rudolf Schottlaender, hrsg. von Eckhard Keßler. Mit den zugehörigen Abbildungen aus der deutschen Ausgabe Augsburg 1532 (Humanistische Bibl. 2,18, München 21988). - Aus der Fülle der Sekundärliteratur sei hervorgehoben Klaus Heitmann, Fortuna und Virtus. Eine Studie zu Petrarcas Lebensweisheit (Köln, Graz 1957).

48 Alfarabi, Über den Ursprung der Wissenschaften (De ortu scientiarum). Eine mittelalterliche Einleitungsschrift in die philosophischen Wissenschaften, hrsg. von Clemens Baeumker (Beitr. z. Gesch. d. Phil. d. MAs 19,3, Münster 1916). Für unseren Zusammenhang wichtiger noch, aber nur in der mir nicht zugänglichen Ausgabe Alpharabi Opera (Paris 1638) gedruckt: De scientiis (Buch der Aufzählung der Wissenschaften); vgl. Moritz Steinschneider, Die europäischen Übersetzungen aus dem Arabischen bis Mitte des 17.Jahrhunderts (ND Graz 1956) 22 und 44 sowie C. Baeumker, 2 f.; weitere Lit. bei Peter Schulthess, Ruedi Imbach, Die Philosophie im lateinischen Mittelalter. Ein Handbuch mit einem bio-bibliographischen Repertorium (Zürich, Düsseldorf 1996) 378f.; vgl. auch Repertorium edierter Texte des Mittelalters aus dem Bereich der Philosophie und angrenzender Gebiete, hrsg. von Rolf Schönberger und Brigitte Kible (Berlin 1994) Nrr. 10221-10290.

${ }^{49}$ Ludwig Baur, Dominicus Gundissalinus: de divisione philosophiae, hrsg. und philosophiegeschichtlich untersucht. Nebst einer Geschichte der philosophischen Einleitung bis zum Ende der Scholastik (Beitr. z. G. d. Phil. d. MAs 4,2-3, Münster 1903); vgl. auch Repertorium (wie Anm. 48) Nrr. 12449-12458. 
dem 12.Jahrhundert berücksichtigt, doch sind - wie wir noch sehen werden: aus guten Gründen - Hugo von St. Viktor und der Policratus, also Johann von Salisbury, je neunmal herausgestellt. Bernhard von Clairvaux habe ich fünfmal gefunden, dazu einmal den Pariser Kanzler Guillerinus mit seinem De universo ${ }^{50}$.

Im ersten Buch werden, wie schon angedeutet, alle weltlichen Lebensformen diskutiert und examiniert auf ihre commoda et incommoda, dulcia et amara, favores et labores, solacia et miserie, facilitates et difficultates, prospera et adversa, quietudines et pericula ${ }^{51}$; auch meine Kurzformulierung „Lob und Tadel“ kommt wenigstens zur Hälfte vor: de laudibus... ${ }^{52}$. In der Regel gibt es für jeden Stand zwei Kapitel, eines Pro, das andere Contra. Hierarchisches Vorgehen ist angestrebt, aber nicht streng durchgehalten: 1. Kaiser, Könige und andere principes (c. 1 u. 2); 2. die Hofleute, curiales (c. 3 u. 4); 3. der Adel, mit den Problemen von Geburtsund Tugendadel (c. 5 u. 6); 4. weiter über den Adel unter besonderer Berücksichtigung der Herolde, precones (c. 7 u. 8); 5. das Militär, die Ritterschaft, armata militia (c. 9 u. 10); 6. (eingeschoben) über Ehe und Jungfräulichkeit (c. 11 u. 12); 7. Magistrat und Richter (c. 13 u. 14); 8. Konsuln und Provinzvorsteher (c. 15 u. 16); 9. Advokaten (c. 17 u. 18); 10. Notare, Tabellionen und Schreiber (c. 19 u. 20). Es folgt - gleichsam vorgezogen, weil nach seiner Systematik an sich den artes mechanicae zugehörig - 11. der Bauernstand (c. 21 u. 22). Dann erst kommt der Block De artibus mechanicis (c. 23-34), sodann die Kapitel De artibus liberalibus (c. 35-40). Den Abschluß bildet ein Epilog in drei Kapiteln, in denen die Mißlichkeiten weltlichen Daseins, ihre Gründe und Konsequenzen ausgebreitet werden (c. 51-53).

Ich habe das Inhaltsverzeichnis deshalb so genau repetiert, um die Bedeutung des Speculum vite bumane für die Handwerksgeschichte zu relativieren. Die so beachtenswerte Verbreitung und Rezeption des Spiegels menschlichen Lebens bis in das 17.Jahrhundert dürfte dem ganzen Werk, nicht aber einzelnen Teilen oder

50 c. 38 fol. $57 \mathrm{r}$; deutsch in Steinhöwels Autograph, fol. 314r Gwilherinus Canczler zu paris, im Druck fol. 81r gwillerinus cantzler zu paryß. Gemeint ist offenkundig Wilhelm von Auvergne (gest. 1249), dessen De universo Teil seines Magisterium divinale war; vgl. Schulthess und Imbach, (wie Anm. 48) 443; vgl. auch Repertorium (wie Anm. 48) 443 Nrr. 1325613267, bes. 13262: Guillelmus Alverniensis De universo opus celeberrimum et singulare, in: Opera omnia I (Paris 1674, ND Frankfurt (Minerva) 1963) 693-1074; Gabriel Jüssen, Wilhelm von Auvergne und die Transformation der scholastischen Philosophie im 13. Jahrhundert, in: Philosophie im Mittelalter, hrsg. von Beckmann, Honnefelder, Schrimpf, Wieland (Hamburg 21996) 141 ff. - Die Namensform Guillermus Parisiensis war in der Inkunabelzeit geläufig, jedoch war dann oft der Dominikaner Wilhelm von Paris, der 1437 eine mehr als hundertmal gedruckte Postilla verfaßte, gemeint; vgl. Frederick R. Goff, The Postilla of Guillermus Parisiensis, in: Gutenberg-Jb. (1959) 73-78; Gottfried Langer, Von der ,Mora' und deren Jahrzahl in der Postilla des Guillermus Parisiensis, in: Gutenberg-Jb. (1971) 82-90; Der Buchdruck im 15. Jahrhundert. 1. Bibliographie (Stuttgart 1988) 105. Auch er erscheint, z. B. in einem Druck von 1482, als Guillerinus. Vgl. Wilhelm Ludwig Schreiber, Handbuch der Holz- und Metallschnitte des XV.Jahrhunderts X,1 (Stuttgart ${ }^{31969)}$ Nr. 4144.

$511 \mathrm{v}$ und $4 \mathrm{rv}$.

52 Z.B. in der Kapitelüberschrift von c. 7: $4 \mathrm{v}$ und $20 \mathrm{v}$. Der Gegenbegriff ist nicht vituperatio o.ä., sondern miseria o.ä., also Elend. 
Blöcken zu verdanken $\operatorname{sein}^{53}$. Immerhin bleibt zu unterstreichen, daß überhaupt die artes mechanicae so nachhaltig berücksichtigt worden sind.

Handwerksgeschichtlich sind, wie ich meine, die Ausführungen des auf der Engelsburg seine Zeit nutzenden spanischen Bischofs vornehmlich aus zwei Gründen relevant. Zum einen wegen der systemtheoretischen, sozialphilosophischen Zuordnung der als Handwerk begriffenen artes mechanicae, und zum anderen wegen der in dieser intensiven und geradezu schulmeisterlich die Positiva und $\mathrm{Ne}$ gativa auflistenden Art kaum ihres Gleichen findenden Betrachtung der einzelnen „Handwerke“. Als dritter Grund wäre vielleicht noch hinzuzufügen, daß er - sei es aus Überzeugung, wofür spricht, daß er sich auch schon in seinem Erziehungstraktat ganz ähnlich geäußert hat ${ }^{54}$, sei es aus dem Zwang seiner Rahmenhandlung, sei es im Nachvollzug vergleichbarer und gelegentlich auch von anderen schon geäußerter Ansichten ${ }^{55}$ - der individuellen Neigung und von der Natur gegebenen Fähigkeit bei der Berufswahl Standesschranken überspringende Eigenbestimmung für möglich und erlaubt hält.

Zur systemtheoretischen Verortung: Für das Sozialschema sind zwei Fragen vorrangig zu beantworten:

1. Was ist in genere unter den artes mechanicae zu verstehen und wieviele Typen gibt es, denen die anderen im einzelnen zuzuordnen sind?

2. Welchen gesellschaftlichen Nutzen haben diese artes und wie ist ihre Wertung im gesamtsozialen Gefüge?

Arévalo gibt in den Kapiteln 23 und 24 seine Antworten, die ich hier nur knapp zusammenfassen und noch knapper mit anderen Modellen vergleichen kann.

${ }^{53} \mathrm{Zu}$ beachten ist in diesem Zusammenhang auch die Aufmerksamkeit, die das zweite, den geistlichen Ständen gewidmete Buch auf sich zog. Der papalistische Verfasser war nämlich ein schonungsloser Zeitkritiker, so daß im 16. Jahrhundert Flacius Illyricus meinte, ihn unter die Zeugen der evangelischen Wahrheit aufnehmen zu sollen; vgl. Mathias Flacius Illyricus, Catalogus testium veritatis, qui ante nostram aetatem reclamarunt Papae (Basel 1556) 949 (zum Jahr 1464); Toni, (wie Anm. 29) 232. Die Ausgaben des Speculum von 1603 (Hannover) und 1683 (Frankfurt) gelten als „protestantisch“; vgl. Lambert, (wie Anm. 29) 1659; Trame, (wie Anm. 29) 168. - Ein Zeugnis dafür, daß aber auch die artes-Kapitel für sich zur Kenntnis genommen wurden, bietet der Augsburger Humanist Sigmund Gossembrot mit seiner Notiz in einer u. a. auch Dicta elicita de libro rerum familiarum et de epistolis Franc. Petrarchae enthaltenen Handschrift: Vide de liberalibus et illiberalibus seu mechanicis scienciis et quare ita dicantur in speculo humane vite Rhodorici in codice...; vgl. Agostino Sottili, I Codice del Patrarca nella Germania occidentale IV, in: Italia medioevale e umanistica 13 (1970) $281 \mathrm{ff}$., hier 299 unter Hinweis auf clm 114/3941. Zu clm 3941, in der Gossembrot auf fol. $28 \mathrm{ff}$. handelt De architectura et pictura lanificii, armaturae, navigationis, agriculturae, venationis, vgl. Catalogus codicum latinorum bibliothecae regiae Monacensis 1,1 (München 21892) 154-156. 54 Speculum c. 23, bes. fol. 41r. - De arte... erudiendi (wie Anm. 37, Nr. 1) 214f., c. 9: Quod iuvenes ad illa conari debent at (!) que illos melios natura disponit.

$55 \mathrm{Zu}$ Roger Bacon vgl. Keniston, (wie Anm. 37, Nr. 1) 215, Anm. 18 mit Hinweis auf dessen Opera hactenus inedita 5 (Oxford 1920) 136f. - Deutlich auch Marsilius von Padua, Defensor (wie Anm. 11) 34-36 (D. 1, c. 7). Daß gleichwohl eine freie Berufswahl wegen ungleichmäßigem, unkontrolliertem Wachstum in dem von Marsilius beschriebenen Staat nicht möglich ist, betont und belegt Tilman Struve, Die Entwicklung der organologischen Staatsauffassung im Mittelalter (Monogr. z. Gesch. d. MA 16, Stuttgart 1978) $269 \mathrm{f}$. 
Zunächst noch der Hinweis, daß die artes mechanicae in der deutschen Übersetzung durch Steinhöwel bezeichnet werden als hantwerck, handtwercke, gelegentlich auch als bantkünste, eine Synonymität, die durchaus üblich war und seit dem 13. Jahrhundert bezeugt ist ${ }^{56}$.

Unser Spanier setzt als bekannt voraus, daß es sieben mechanische Künste gibt, auf die alle anderen den Leib betreffenden Handwerke zurückzuführen sind: 1. lanificium (Steinhöwel: wollen werck); 2. armatura sive fabrilis (marner, waffenoder schmid werck); 3. navigatio (schiffung oder fart); 4. agricultura (ackerbaw/ agkerbew); 5. venatio (iägeri); 6. medicina (artznei); 7. theatrica (freudenspil). Als Autorität beruft er sich auf Aristoteles im 7. Buch der Politik ${ }^{57}$, übernimmt die Aufzählung, Reihung und Untergliederung - z.B. beim lanificium mit den Worten: texendi, torquendi, suendi; ... acu, fuso, rota, fibula; ... lana, lino, pelle, pilo und viminibus - aber dem an anderer Stelle genannten Didascalicon des Hugo von St. Viktor, wo lediglich statt artes mechanicae scientiae mechanicae steht, wie es seit dem Beginn des 13. Jahrhunderts üblich war ${ }^{58}$. Arévalo wußte wohl, daß die

56 Z.B. in einem Zunftbrief für die Schneider Basels von Bischof Berthold II. vom 14. Nov. 1260: genus hominum ... artes mechanicae exercencium, qui dicuntur vulgariter hantwerchlute, UB Stadt Basel I (1890) 290f. Nr. 388; vgl. mit weiteren Beispielen Sternagel, (wie Anm. 1) $56 \mathrm{f}$.

57 Arévalo schwimmt damit im Strom der Theoretiker des 14. und 15. Jahrhunderts; vgl. die Lit. in Anm. 77.

58 Speculum c. 25 fol. 45r; in Anlehnung an Hugo, Didascalicon II, c. 21; scientiae bzw. scientias bei Hugo c. 20 (Divisio mechanicae in septem). - Erwähnung von bugo de sancto victore im Speculum zuerst c. 12 fol. 29r, von bugo in suo didascolicon (!) im Speculum zuerst c. 24 fol. 44r, dann Hugo in didascolicon im Speculum c. 35 fol. 53r. - Zur Ersetzung von scientia durch ars vgl. Sternagel, (wie Anm. 1) $95 \mathrm{f}$. - Zitiert wird hier und im folgenden nach der Ausgabe von Charles Henry Buttimer, Hugonis de Sancto Victore Didascalicon De Studio Legendi. A Critical Text (The Catholic University of America. Studies in medieval and renaissance latin 10, Washington D.C. 1939). - Ältere Ausgabe der Eruditionis didascalicae libri VII bei Migne PL 176, 741-838, dazu MPL 177, 193-204 Excerptionum allegoricarum, L. 1: Tractat de origine et divisione artium continet capitula 25; Übersetzung ins Englische und ausführliche Bibliographie: The Didascalicon of Hugh of St. Victor. A medieval guide to the arts. Translated from the Latin with an introduction and notes by Jerome Taylor (Rec. of Civil., Sources and Studies 64, New York and London 1961), wo (3) die Fertigstellung des Werkes in Paris auf die späten 20er Jahre des 12. Jahrhunderts datiert wird; Übers. ins Italienische: Ugo di San Vittore, Didascalicon, I doni della promessa divina, L'essenza dell' amore, Discorso in lode del divino amore, Introduzione, traduzione e note di Vincenzo Liccaro (I Class. del pensiero. S. 2, Milano 1987); ins Französische: Hugues de Saint-Victor, L'art de lire. Didascalicon. Introduction, traduction et notes par Michel Lemoine (Les Éditions du Cerf, Paris 1991); vgl. auch Repertorium (wie Anm. 48) Nrr. 14048-14161, bes. Nrr. 14109-14112; Rudolf Goy, Die Überlieferung der Werke Hugos von St. Viktor. Ein Beitrag zur Kommunikationsgeschichte des Mittelalters (Monogr. z. Gesch. d. MA 14, Stuttgart 1976) 14-36. - Angesichts der zentralen Rolle, die Hugo von St. Viktor in der artes mechanicae-Theorie spielt, scheint es überflüssig, hier mit einer die Literaturliste in Anm. 1 oder bei Taylor wiederholenden Bibliographie aufzuwarten; neuester allgemeiner Einstieg bei Schulthess und Imbach, (wie Anm. 48) 471; zu den jüngsten einschlägigen Veröffentlichungen zählt wohl Günther Mesching, Kontemplation und Konstruktion. Zum Verhältnis von Mystik und Wissenschaft bei Hugo von St. Viktor, in: Scientia und ars im Hoch- und Spätmittelalter, hrsg. von Ingrid Craemer-Ruegenberg, Andreas Speer (Miscell. Mediaevalia 22,2, Berlin, New York 1994) 589-602. 
von dem Viktoriner in den späten 20er Jahren des 12.Jahrhunderts in Analogie zu den artes liberales aufgestellte Siebenerreihe nicht unumstritten war und daß insbesondere etliche die mercatura, die kaufmansschafft, die bei Hugo der navigatio subsumiert war, für sich selber setzen ${ }^{59}$. Ähnliches gilt für die medicina ${ }^{60}$, und es dürfte ihm klar gewesen sein, daß seit dem induktiven Vorgehen von Albertus Magnus und Thomas von Aquin eine verbindliche Wissenschafts- und Fächereinteilung der artes mechanicae für viele theoretisch obsolet geworden war und ohnehin im Bereich der ermahnenden, lobenden und tadelnden didaktischen Literatur im allgemeinen gar nicht Verwendung fand ${ }^{61}$. Trotzdem wäre es verfehlt, seine Ausführungen als unzeitgemäßen Traditionalismus abzuqualifizieren. Das Festhalten an überkommenen Deutungs- und Einordnungsmustern war durchaus zeittypisch und zeitgemäß, mußte nicht museal, sondern konnte auch orientierungsstiftende Normbesinnung sein ${ }^{62}$. Als Belege dafür, daß das Speculum des Bischofs von Zamora mit seiner Aufzählung und systematischen Zuweisung der artes im Rahmen des zu Lebzeiten Arévalos Möglichen, vielleicht sogar Üblichen blieb, verweise ich aus meiner märkischen Heimat auf den Dekalogkommentar des Bi-

59 Speculum c. 23, fol. 41v; Spiegel, c. 23, fol. 54r; gedacht haben könnte er u. a. an Konrad von Megenberg, (wie Anm. 2) 95 (I,2, c. 17... Sunt enim tres status popularium hominum... militaris, mercaturi et mechanici artiste). Ältere Untergliederung der plebs in artifices, negotiatores und agricolas u. a. bei Bonizo, Liber de vita christiana, hrsg. von Ernst Perels (Berlin 1930) $252 \mathrm{f}$. Von den vielen Zeitgenossen Arévalos, die deutlich zwischen mechanicis und mercatoribus unterschieden, sei nur Jakob von Paradies (von Jüterbog u.ä.) erwähnt; vgl. Jakub z Paradyza, Opuscula inedita, hrsg. von Stanislaw Andrzej Porebski (Textus et studia historiam theologiae in Polonia excultae spectantia 5, Warszawa 1978) 290; zum Verf. vgl. Dieter Mertens, (Art.) Jakob von Paradies, in: Verf.lex. 4 (1982) 478-487.

${ }^{60}$ Schon Vincenz von Beauvais nahm in Korrektur von Richard (!) von St. Viktor die Medizin aus der Reihe der sieben artes mechanicae, weil sie etiam in mentis speculatione consistit, und setzte an ihre Stelle die Alchemie; Vincentius Bellovacensis, Speculum doctrinale XI c. 105 (Duai 1624; ND Graz 1965) 1053 f.; vgl. auch Lusignan, (wie Anm. 16) 36 und Ovitt, (wie Anm. 16) 100. Im Speculum historiale (S. 21) I c. 54 hat die Medizin ihren angestammten Platz in der Siebenerreihe.

61 Vgl. Sternagel, (wie Anm. 1), bes. die Abschnitte 10 (Albertus Magnus und Thomas von Aquin) 103-117 und 11 (Ausblick auf das späte Mittelalter) 118-124. Arévalo ist von Sternagel nicht berücksichtigt worden. - Die Präponderanz der Nichtnutzung des septem artes mechanicae-Schemas in der didaktischen Literatur, angefangen bei den sermones nulli parcentes (Buch der Rügen) und den geistlichen Spielen, über den ,Renner' Hugos von Trimberg und ,Des Teufels Netz' bis hin zu Brants, Narrenschiff' und zu Hans Sachs, ist so eindeutig, daß auf Einzelbelege hier verzichtet werden kann.

$62 \mathrm{Vgl}$. Rainer und Trudel Woblfeil, Verbildlichungen ständischer Gesellschaft: Bartholomäus Bruyn d. ̈. - Petrarcameister, in: Ständische Gesellschaft und soziale Mobilität, hrsg. von Winfried Schulze (Schr. d. Hist. Kollegs, Kolloquien 12, München 1988) 269-332, bes. $318 \mathrm{f}$. Für das komplexe Verhältnis von ,Schemata der Deutung' und ,Schemata der Erfahrung' und dem Wirklichkeitsbezug dieser Schemata sei nachdrücklich verwiesen auf Gerhard Oexle, Die funktionale Dreiteilung als Deutungsschema der sozialen Wirklichkeit in der ständischen Gesellschaft des Mittelalters, in: Schulze , (wie eben) 19-51. - Die „Diskrepanz zwischen gelehrter Konstruktion und sozialer Wirklichkeit" betont hingegen Boebm, Die artes (wie Anm. 1) 432; ähnliche Skepsis bei Riha, Defizit (wie Anm. 1) 265. 
schofs Stephan Bodeker von 1446-144963 und besonders auf einen etwa gleichzeitig entstandenen Bilderzyklus, der mit seinen Begleittexten wie eine vorweggenommene kommentierte Illustration des Speculum ausgesehen hat und eine didaktische Veranschaulichung des artes-Systems bot. Er schmückte die Bibliothekswände des vielleicht schönsten und eindrucksvollsten Kirchenbaus der Region, des Prämonstratenser Marienstifts auf dem Harlunger Berg bei Brandenburg. Leider ist der Gebäudekomplex nach der Reformation erst verfallen und dann restlos abgetragen worden, doch ist es zwei eigenhändigen Ausfertigungen der „Beschreibung“ dieser Picture nobiles septem arcium liberalium et mechanicarum, theologie et medicine cum pulcerrimis sentenciis philosophorum durch Hartmann Schedel (1463-1465) sowie den Forschungen von Karl-August Wirth zu verdanken, daß recht genaue Aussagen gemacht werden können, die für unseren Zusammenhang selbst dann ihr Gewicht behielten, wenn die Beschreibung des Nürnberger Patriziers nur die Wiedergabe eines gar nicht zur Ausführung gelangten Programmkonzepts gewesen sein sollte ${ }^{64}$.

Im Bereich der artes mechanicae finden wir also - und das ist für die Einordnung unseres Spaniers eine wesentliche Hilfe - eine fast identische Systematisierung mit der Reihenfolge: lanificium, armatura, navigatio, agricultura, venacio und teatrica ${ }^{65}$. Lediglich die medicina ist bereits vorher abgehandelt und findet

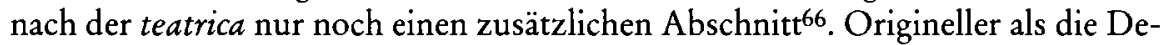
finitionen der artes bei Schedel, die er weitgehend derselben Vorlage wie Arévalo entnimmt, nämlich dem Didascalicon des Hugo von St. Viktor ${ }^{67}$, sind seine Beschreibungen oder Programme der Bilder. Hier werden Einblicke in den Handwerksalltag eindringlich vermittelt, wobei die pictura zum lanificium besonders deutlich die Zusammenarbeit und die Arbeitsteilung von Mann und Frau bei Her-

${ }^{63}$ Auf Bitten der um den Umfang und den Charakter des Colloquium-Bandes besorgten Schriftleitung ist ein Anhang 4 über ,Die artes mechanicae im Dekalogtraktat des Brandenburger Bischofs Stephan Bodeker' mit einer die Wirkung Hugos von St. Viktor belegenden Teiledition aus den Erklärungen zum dritten Gebot hier nicht gedruckt worden.

${ }^{64}$ Auf die Notizen von Schedel haben m. W. zuletzt hingewiesen Knut Schulz, Handwerk und Gewerbe im spätmittelalterlichen Brandenburg, in: Beiträge zur Entstehung und Entwicklung der Stadt Brandenburg im Mittelalter, hrsg. von Winfried Schich (Veröff. d. Hist. Komm. zu Berlin 84, Berlin, New York 1993) 175-201, bes. 175-177, und Dietrich Kurze, Schulen in der mittelalterlichen Stadt Brandenburg, in: W. Schich, (wie eben) 227-277, bes. 242-250, der sich vorwiegend der Lokalisierungsfrage zuwendet. - Die einschlägigen Abhandlungen von Karl-August Wirth, die die ältere Literatur obsolet machen, sind bei $K$. Schulz und $D$. Kurze aufgeführt. An dieser Stelle muß der Hinweis genügen auf K.A. Wirth, Eine bekannte Quellenschrift - neu gelesen, in: Münchener Jb. d. bildenden Kunst 3,25 (1974) 47-76, weil sich dort (50-62) die neueste, im folgenden zitierte Edition befindet. Vgl. auch Anm. 53 am Ende! - In den brandenburgischen Zusammenhang fügt sich übrigens recht sinnvoll ein, daß die Bibliothek des Domstiftes auch ein Exemplar des im Januar 1471 in Augsburg gedruckten Speculum besaß; vgl. Gustav Abb, Gottfried Wentz, Das Bistum Brandenburg 1 (Germania Sacra 1,1,1, Berlin 1929, ND 1963) 95.

65 Wirth, (wie Anm. 64) 56-60.

66 Wirth, 33 f. bzw. $60 \mathrm{f}$.

$67 \mathrm{Vgl}$. Anm. 58. 
stellung, Bearbeitung und Verkauf von Tüchern, bei der Fabrikation von Seilen, beim Wollschlagen, Nähen, bei der Anfertigung von Schuhen, bei der Flickschusterei und beim Wickeln von Garn auf die Haspel visualisiert ${ }^{68}$. Die vom Rom Arévalos räumlich weit entfernt liegenden, aber gerade deshalb tragfähigen Belege aus der Mark Brandenburg für die Nutzung der artes-Systematik viktorinischer Prägung finden nach dem Tod des Kastellans der Engelsburg nicht nur durch die Drucke seines Speculum ihre Fortsetzung, etwa in der Margarita philosopbica des Gregor Reisch (ca. 1470-1575), wo die philosophia practica unterteilt wird in philosophia activa mit Ethik, Politik, Ökonomik und Monastik und in philosophia factiva mit den sieben Tätigkeitsgruppen vom lanificium bis zur theatrica69. Selbst die leicht abweichende Benennung der septem mechanicae in dem Holzschnitt von Hans Burgkmair (von 1507), der gewöhnlich als „Der allegorische Reichsadler des Celtis" bezeichnet wird, spricht eher für als gegen die Normalität der Speculum-Auffassung, zumal deren wichtigste Basis, das Didascalicon des Hugo von St. Viktor, auch in der Inkunabelzeit noch mehrfach - und sicher nicht lediglich aus antiquarischem Interesse - gedruckt wurde 70 .

Eine gewisse Enttäuschung bereitet, daß Arévalo ebensowenig wie die vergleichbaren Quellen ähnlichen Typs bei seiner Auflistung eine deutliche Hierarchisierung der sieben Handwerksgruppen vornimmt und dann bei der Beschreibung der mannigfachen Teilgewerbe - also z. B. in der Gruppe armatura, Abteilung fabrilis, Waffenschmiede und Goldschmiede nennend ${ }^{71}$ (Steinhöwel erwähnt außerdem Rotschmiede, Harnischmacher, Schlosser, Kantengießer, Münzer und Büchsenmeister $^{72}$ ) - nicht auf die Reputations- und Repräsentationsdifferenzen innerhalb der Berufsgruppen eingeht und insofern die soziale Wirklichkeit ganz ungenügend widerspiegelt. Nur der ars medicine bestätigt er, sie sei inter mechanicas nobilior (c. 32).

68 Wirth, 36f.; vgl. zu dieser Passage auch Schulz, (wie Anm. 64) 176 und unten Anhang 3.

69 Eine reiche Fundgrube auch für die artes mechanicae bietet an Karl-August Wirth, Von mittelalterlichen Bildern und Lehrfiguren im Dienste der Schule und des Unterrichts, in: Studien zum städtischen Bildungswesen des späteren Mittelalters und der frühen Neuzeit, hrsg. von Bernd Moeller, Hans Patze, Karl Strackmann. Redig. von Ludger Grenzmann (Abh. d. Akad. d. Wiss. in Göttingen, phil.-hist. Kl. 3,137, Göttingen 1983) 256-370. Speziell zu Reisch vgl. G. Münzel, Der Kartäuserprior Gregor Reisch und die Margaritha philosophica (Freiburg 1931); Robert von Srbik, Die Margaritha philosophica des Gregor Reisch (Wien 1941); Wirth, (wie oben) bes. 292 f.; zuletzt Zahlten (wie Anhang 3, Anm. 5).

$70 \mathrm{Vgl}$. Wirth, (wie Anm. 69) bes. $338 \mathrm{mit}$ Hinweis auf Tilman Falk, in: (Ausstellungskatalog) 1473-1973. Hans Burgmair. Das graphische Werk (Augsburg 1973) Nr. 17, Abb. 20, mit der älteren Lit. - Zehn frühe Drucke verzeichnet Buttimer, (wie Anm. 58) XLV-L; Handschriften auch des 15. Jahrhunderts bei Goy, (wie Anm. 58) 14-35.

71 c. 26 , fol. $45 \mathrm{v}, 46$; fabri, aurifices.

72 c. 18 , fol. 42 r, 43 r; c. 23 , fol. $53 \mathrm{v}$; c. 26, fol. 40v, 41r. - Bekanntlich ging die Binnendifferenzierung mit Huf- und Nagelschmieden, Kesselmachern, Kesselflickern usw. noch viel weiter. Schon im 12. Jahrhundert meinte Johann von Salisbury zu den multae species lanificii artesque mecanicae, daß quidem prae multitudine numerari non possunt; Ioannis Sarisberiensis episcopi Carnotensis Policratici ... libri VIII, recog. Clemens C.I. Webb (Oxford 1909), T. II 58f. (Lib. 6 c. 20). 
Zur zweiten oben gestellten Frage, der nach dem gesamtgesellschaftlichen Nutzen der artes mechanicae und ihrer Positionierung im allgemeinen weltlichen Sozialgefüge im Speculum müssen Andeutungen genügen.

Bei seinen Ausführungen über Notwendigkeit und Nutzen der mechanischen Künste ist Arévalo, wie es nach der vorhin referierten Autorenliste auch nicht anders erwartet werden kann, sowohl der jüdisch-christlichen als auch der heidnisch-antiken Tradition verpflichtet, wobei jedoch, wie mir scheint, der Verweis auf den Sündenfall und die nachparadiesischen Zwänge hinter die Zivilisationstheorien der Philosophen und das göttliche Arbeitsgebot hinter die fürsorgende Mutter Natur ${ }^{73}$ in die zweite Reihe verdrängt werden, obwohl der Spanier die ihm durch Hugo von St. Viktor gebotene Chance, beispielsweise den usum lanificii auf Minerva zurückzuführen ${ }^{74}$, nicht einmal genutzt hat.

Ohne die Handwerke ist menschliche Zivilisation nicht vorstellbar: ohne Akkerbau keine Nahrung; ohne venatio keine Zubereitung von Speise und Trank; ohne lanificium müßten die Menschen nackt laufen, könnte ihre Scham nicht verbergen, wären Hitze und Kälte ausgesetzt; ohne Schmiede und Zimmerleute müßten sie wie wilde Tiere in den Höhlen wohnen und könnten sich nicht vor Feinden schützen; ohne navigatio würde die tota pene societas hominum, die tota conversatio untergehen usw. ${ }^{75}$ Und doch sind die Handwerker für Arévalo wie für die meisten, eher konservativen Sozialtheoretiker - Ausnahmen sind am ehesten im hussitisch-brüdergemeindlichen Umfeld zu finden ${ }^{76}$ - politisch nur Menschen zweiter Klasse. Wiederholt und nur zu gerne zitiert er aus Aristoteles „Politik“, wonach lediglich die consiliativos, sacerdotes, bellantes et iudicativos es verdienen, veros cives genannt zu werden, während Bauern, Kaufleute, Handwerker und Händler, bei aller Notwendigkeit für die Stadt, nicht zu ihren wahren Teilen gehören, nicht im eigentlichen Sinne Bürger sind (non proprie esse cives), denn sie sind nicht auf Tugend, sondern nur auf ihren eigenen Nutz bedacht. Ungeschickt sind sie zu raten, zu richten und ein öffentliches Amt wahrzunehmen. Hierfür bedürfe es der Klugheit und subtilen Sinnes. Darum sind die Handwerke von denen zu

73 Zum Problem vgl. mit weiterführenden Angaben Klaus Schreiner, Si homo non peccasset .... Der Sündenfall Adams und Evas in seiner Bedeutung für die soziale, seelische und körperliche Verfaßtheit des Menschen, in: Gepeinigt, begehrt, vergessen: Symbolik und Sozialbezug des Körpers im späten Mittelalter und in der frühen Neuzeit, hrsg. von Klaus Schreiner, Norbert Schnitzler (München 1992) 41-84. - z. B. Speculum c. 23, fol. 41 r (parens natura, provida gubernatrix natura); Spiegel fol. 53v (vnsere muter die natur).

74 Hugo, Didascalicon L. 3, c. 2: De auctoribus artium, in der o. Anm. 58 genannten Ausgabe S. 48 f. bzw. MPL 176, 766, und MPL 177, $202 \mathrm{f}$. (c. 24: De inventoribus artium).

75 Speculum c. 25-33.

76 Vgl. Miloslav Polivka, Mittelalterliche Erstarrung und neuzeitliche Dynamik. Hussitische Revolution als Katalysator von Veränderungen der Vorstellungen über das gesellschaftliche System, in: Das Mittelalter - unsere fremde Vergangenheit, hrsg. von Joachim Kuolt, Harald Kleinschmidt, Peter Dinzelbacher (Flugschr. d. Volkshochsch. Stuttgart NF 6, Stuttgart 1990) 269-297; Wojciech Iwanczak, Mittelalterliche Dilemmeta. Die Stadt und die Lehre von den drei gesellschaftlichen Ständen, in: Arch. f. Kult. Gesch. 74 (1992) 49-81. 
treiben, die, wie Steinhöwel es verdeutscht, bessers nit entkunnent ${ }^{77}$. Kein Wunder unter diesen Umständen, daß Arévalo die wohl in irischen Mönchskreisen am Ende des 9. Jahrhunderts aufgekommene und seit Hugo von St. Viktor zum etymologischen Allgemeingut gewordene sprachliche Ableitung der mechanica ars von moecho/mecho, von moechus = adulter, also im Sinne von ,ehebrecherisch, vorspiegelnd, uneigentlich, dem Leib und nicht der Tugend zugeordnet", weidlich ausschlachtet ${ }^{78}$. Organologische Metaphern - wie sie beispielsweise Johannes Rothe in seinen Ratsgedichten systematisch benutzt, um den Minderstatus der Handwerker festzuschreiben ${ }^{79}$ - sind im Speculum nur selten zu finden ${ }^{80}$.

Ganz abgesehen von der allgemeinen sozialtheoretischen Zuordnung der artes mechanicae zu der ,uneigentlichen' Bürgerschaft singt Arévalo auch kräftig im

77 Speculum c. 9 (de armata militia et exercitio armorum... et an... sunt veri ciues et partes ciuitatis); bes. fol. $24 \mathrm{v}$ und $25 \mathrm{r}$ (Spiegel, fol. $27 \mathrm{v}$ ), c. 24 (de diuisione in genere vite mechanice, et quomodo licet sint artes necessarie: tamen non est necessarium (!) illarum habere exercitium...); bes. fol. 43v, 44r (Spiegel, fol. 57v). - Zum gesamten Denkrahmen, in den Arévalo einzuordnen wäre, handelt ausführlich Ulrich Meier, Mensch und Bürger. Die Stadt im Denken spätmittelalterlicher Theologen, Philosophen und Juristen (München 1994); ders., Molti revoluzioni, molte novità. Gesellschaftlicher Wandel im Spiegel der politischen Philosophie und im Urteil der städtischen Chronisten des späten Mittelalters, in: Sozialer Wandel im Mittelalter. Wahrnehmungsformen, Erklärungsmuster, Regelungsmechanismen, hrsg. von Jürgen Miethke, Klaus Schreiner (Sigmaringen 1994) 119-176; ders., Burgerlich vereynung. Herrschende, beherrschte und ,mittlere' Bürger in Politiktheorie, chronikalischer Überlieferung und städtischen Quellen des Spätmittelalters, in: Bürgerschaft. Rezeption und Innovation der Begrifflichkeit vom Hohen Mittelalter bis zum 19. Jahrhundert, hrsg. von Reinhart Koselleck, Klaus Schreiner (Sprache und Geschichte 22, Stuttgart 1994) 43-89 (jeweils mit zahlreichen Literaturhinweisen und Berücksichtigung der einschlägigen Aristoteleszitate und deren Rezeption). Zur Ablehnung der Teilhabe ungebildeter Handwerker an der Stadtführung in der sonstigen didaktischen Literatur, z. B. in "Des Teufels Netz", vgl. u. a. Hoffmann, (wie Anm. 8) 49. Zur tatsächlichen Sozialstruktur vgl. mit der dort gebotenen Bibliographie Eberhard Isenmann, Die deutsche Stadt im Spätmittelalter (UTB Gr.R., Stuttgart 1988) 245-290.

78 Z.B. c. 24, fol. 44v: Vocantur autem mechanice secundum philosophum et secundum Alfarabium et Hugonem in didascolicon (!) quasi adulterine; in der deutschen Fassung (fol. 58v: ze latein artes mechanice, daz ist eebrüchige künsten genennet) sind die Autoritäten nicht mit aufgeführt. Zu der in der Fachliteratur schon ausreichend wahrgenommenen etymologischen Herleitung vgl. u. a. Sternagel, (wie Anm. 1) $45 \mathrm{ff}$., dort $73 \mathrm{zu}$ mechanica, id est adulterina bei Hugo von St. Viktor; Guy H. Allard, Les arts mécaniques aux yeux de l'idéologie médiévale, in: Allard, Lusignan, (wie Anm. 1) 13-31, bes. 17-19.

79 Johannes Rothes Ratsgedichte, hrsg. von Herbert Wolf (TspMA 25, Berlin 1971). Rothes detaillierter Vergleich der Stadt mit einem Körper, für den ein Haupt notwendig ist, fand seine technisierte Entsprechung in: Hermen Botes Radbuch. In Abbildung des Druckes L ca. 1492/93. Mit dem Text nach Hermann Brandes und einer Übersetzung von Heinz-Lothar Worm, hrsg. von Werner Wunderlich (Göppinger Beitr. z. Textgesch. 105, Göppingen 1985). 80 Z.B. c. 24, Spec., fol. 44r (Spiegel, fol. 57v), unter Bezug auf den Apostel bzw. Paulus. Gemeint ist offenbar 1. Corint. 12, $12 \mathrm{ff}$, jedoch ist der dortige Sinn fast ins Gegenteil verkürzt. - Im zweiten Buch c. 16 (De dignitate et honore officii, thesaurarii vel custodis ecclesie...; Spec. fol. 100r-101v; Spiegel, fol. 136v-138r) wird nach Policratus (d.i. Johann von Salisbury) die Fabel vom Magen und den Gliedern erzählt; zum Problem vgl. Dietmar Peil, Der Streit der Glieder mit dem Magen. Studien zur Überlieferungs- und Deutungsgeschichte der Fabel des Menenius Agrippa von der Antike bis ins 20.Jahrhundert (Frankfurt a.M. u. a. 1985). 
Chor derjenigen mit, die Betrügereien, Untreue und böse List der verschiedenen Handwerke anprangerten ${ }^{81}$. Im lanificium-Kapitel (c. 25) beklagt er die Undankbarkeit der Menschen gegenüber Gott, der Wolle so reichlich wie Schnee gibt ${ }^{82}$, während sie ihn um die Zehnten und die Erstlinge bei den Lämmern betrügen. Und nachdem sie mit Gott in Streit geraten sind, halten sie es für ein Leichtes, auch ihre Nächsten zu verletzen. Sie weben meist zu weiche Tücher, stehlen gute und fügen schlechte Wolle hinzu, geben falsche Farben bei; aus Habsucht mischen sie bei der Kleiderherstellung Wolle und Leinen, berechnen mit falschem Gewicht, und anderes mehr. Die Schmiede (c. 26) stellen unzuverlässige Pflüge und Schwerter her, versuchen, über Wert zu verkaufen, beliefern auch Ungläubige mit Waffen. Goldschmiede arbeiten mit falschen Metallverbindungen, geben Messing für Gold und eine Mischung von Blei und Silber (stannum) für reines Silber aus. Überraschend gut kommen (c. 27) die Seefahrer, sofern sie nicht Piraten sind, weg. Nicht die moralischen Gefährdungen werden aufgezählt, sondern die durch Stürme und Strömungen sowie durch Fische, die wie die Delphine nach Menschfleisch dürsten ${ }^{83}$. Um so ungehemmter kann der Verfasser in c. 33 (De arte mercandi et vendendi, que ipsa mechanica est et sub nauigatoria continetur et de... illius infelicitate, fraudibus, dolis atque periculis) die rhetorische Frage stellen, wer denn nicht in der Lage sei, die Listen, Betrügereien, Ungerechtigkeiten und Verbrechen der Kaufleute aufzuzählen: fälschliche Beanstandungen beim Einkauf, Verschweigen von Schäden beim Verkauf; Verminderung der Maße und der Gewichte; Lügen, Meineide, Verschlagenheit, Habsucht und Wucher ${ }^{84}$. Bei der ars venatoria (c. 28) wird u. a. festgestellt, daß Fleischgenuß vor der Sintflut unbekannt war; im übrigen wisse jeder, daß Schlächter faules Fleisch verkauften, Schaf für Biber, Hirsch für Schafbock und Ziege für Reh ausgäben, beim Gewicht täuschten und die Gesundheit der Käufer gefährdeten. Die gegenwärtigen Bauern (c. 30 u. bes. c. 22) haben längst die alten Tugenden hinter sich gelassen. Statt, wie der Prophet es sagte ${ }^{85}$, Schwerter zu Pflugscharen und Lanzen zu Sicheln zu machen, würden sie nun Ackergeräte zu Waffen umschmieden, und zwar nicht zur Verteidigung, sondern zum Angriff. Gott betrügen sie um den Zehnten und den König um die Steuern. Sie lassen ihre Felder durch Knechte bestellen, usurpieren

$81 \mathrm{Zu}$ den noch wesentlich anschaulicheren und detaillierteren Ergänzungen gerade dieser Bemerkungen des Spaniers durch Steinhöwel siehe unten Anhang 2. - Zur Qualitätsschelte vgl. Gerbard Jaritz, Handwerkliche Produktion und Qualität im Spätmittelalter, in: Handwerk u. Sachkultur (wie Anm. 25) 33-49.

82 Vgl. Psalm 147,16.

83 47r: ... inter delphines conuersari, qui carnes bumanas sitiunt. Arévalo verkürzt hier die u. a. von Vincentius Bellovacensis, Speculum naturale III c. 111 (Lyon 1624; ND 1964) 1306 verbreitete mittelalterliche Ansicht, daß Delphine Fischer, die einmal von ihrem Fleisch gekostet haben, auffressen, sie anderenfalls aber ans Ufer bringen; vgl. mit weiteren Belegen Chr. Hünemörder, (Art) Delphin, in: Lex. d. MAs 3 (1986) $683 \mathrm{f}$.

84 Vgl. zu Ethik der Kaufleute, z.T. mit Angabe von Quellen und Literatur, die meine Hinweise noch ergänzen können, Gerhard Rösch, Wucher in Deutschland. Überlegungen zur Normdidaxe und Normrezeption, in: HZ 259 (1994) 593-636.

85 Anspielung auf Jes. 2,4; Micha 4,3; Joel 4,10. 
Ämter, für die sie nicht geeignet sind, tragen prachtvolle Kleider usw. Im Kapitel über die ars pastoralis (c. 30), die einige dem Ackerbau, andere der Jagd zuordnen, wird an das Prophetenwort von den ungetreuen Sachwaltern erinnert ${ }^{86}$. Bei der ars theatrica (c. 31), die von Christen an unterste Stelle zu setzen ist, läßt Arévalo nur unschuldige, der Erholung dienende Spiele zu und hat es im übrigen leicht, durch Hinweise auf Seneca, Chrysostomus, Augustin und andere Autoritäten die Gefährdungen dieses ,Handwerks' zu benennen. Dem medicina-Abschnitt zufolge hat der Autor viele gesehen, die gestern Drogisten und heute Ärzte waren (heri aromatorios bodie medicos), gestern Bärte schoren und heute schwere Krankheiten beurteilten, gestern Kräuter in Apotheken mischten und heute an Fürstenhöfe Erkrankte berieten. Viele tausend Menschen seien durch die Unwissenheit und Unerfahrenheit solcher Ärzte gestorben. Aber - und das kann nicht genug betont werden - er sang nicht nur im Chor der Tadeler, sondern erhob seine Stimme ebenso laut beim Lob der artes mechanicae.

Im weiten Feld ${ }^{87}$ der spätmittelalterlich-frühneuzeitlichen Stände- und Handwerkerliteratur scheint Arévalos Spiegel des menschlichen Lebens seine, u. a. durch die Vielzahl der Inkunabeln und Frühdrucke schon damals weithin anerkannte Relevanz gehabt zu haben, weil er der selbstgestellten Aufgabe, nämlich umfassend und detailliert, streng systematisierend und doch lebensnah, mit seltener Ausgewogenheit der Argumente seinen Lesern sowohl Orientierungshilfe als auch Entscheidungsmöglichkeit zu bieten, gerecht geworden ist. Dies freilich in den dreifachen und nur ansatzweise durchlässig gemachten Grenzen, die ihm adlige Herkunft, geistlicher Stand und die von ihm genutzten Autoritäten vorgaben.

86 Vgl. Psalm 118, 119.

87 Campus latus ist eine von Arévalo im Speculum und auch sonst gerne genutzte Redensart; vgl. Kurze, Schulen (wie Anm. 64) 276, Anm. 194. 


\section{Anhang 1}

\section{Handschriften und Drucke des Speculum vite bumane und seiner Übersetzungen}

Die folgende Aufstellung will in ihrer bibliographischen Gründlichkeit nicht etwa mit dem „Gesamtkatalog der Wiegendrucke“ oder ähnlichen ausführlichen Hilfsmitteln wetteifern. Ihr Hauptziel ist es, die eindrucksvolle Verbreitungsgeschichte des Speculum zu veranschaulichen. Zu diesem Zweck muß es in der Regel genügen, Erscheinungsdatum, -ort und Drucker anzugeben sowie auf die am zuverlässigsten erscheinenden Hilfsmittel zu verweisen. Für die Inkunabelzeit konnte der noch nicht gedruckte und noch nicht druckreife Teil des Gesamtkataloges der Wiegendrucke genutzt werden. Literaturhinweise zu den Druckern der Inkunabelzeit werden in der Regel nicht angeboten. Sie sind leicht zu finden in: Der Buchdruck im 15. Jahrhundert. Eine Bibliographie, hrsg. von Severin Corsten, Reimar Walter Fuchs, unter Mitarb. von Kurt Hans Staub. 1: Bibliographie; 2: Nachträge und Erg. Die Register (Hiersemanns Bibliographisches Handbuch 7,1.2, Stuttgart 1988 bzw. 1993).

Während es bisher m.W. noch keine Versuche gab, die Handschriften zusammen aufzulisten - erste, aber nicht alle Manuskripte erfassende Hilfe bietet Kristeller, Iter 1-6, - haben für die Drucke, die auch die Nachinkunabelzeit berücksichtigen, in jüngerer Zeit angeboten Toni, (wie oben Anm. 29) 356-359 und Law (wie Anhang 1, A, c, Nr. 1) 111-117, besser jedoch Antonio Palau y Dulcet, Manual del librero hispanoamericano 17 (Barcelona 21965) 178-180 (Nrr. 272017272040), der aber ebenfalls nicht das Optimum erreicht hat und zudem mit bibliographischen Nachweisen geizt.

Bei oft fehlenden Drucker- und Jahresangaben in Inkunabeln ist es zur Zeit nicht möglich, die sich in der Forschungsliteratur findenden lückenhaften oder auch widerspruchsvollen Informationen stimmig $\mathrm{zu}$ ordnen. Zuweisungen mit hohem Wahrscheinlichkeitsgrad werden deshalb mitgezählt, unsichere erhalten keine Nummern, und irrige werden in Klammern gesetzt.

Folgende Abkürzungen finden Verwendung: $\mathbf{A m}=$ Incunabula in American Libraries. A Third Census of Fifteenth-Century Books recorded in North American Collections, reproduced from the annoted copy mainted by Frederick $R$. Goff, Compiler and Editor (New York 1973); Bl = Morton W. Bloomfield, Bertrand-Georges Guyot u.a., Incipit of Latin Works on the Virtues and Vices, $1100-$ 1500 A.D. Including a Section of Incipits of Works on the Pater Noster (Cambridge/Massachusetts 1979); $\mathrm{C}=$ W.A. Copinger, Supplement to Hain's Repertorium Bibliographicum, 2 Bde. (London 1895-1902); $\mathrm{G}=$ Ferdinand Geldner, Die deutschen Inkunabeldrucker. Ein Handbuch der deutschen Buchdrucker des XV. Jahrhunderts nach Druckorten, 1 (Stuttgart 1968), 2: Fremde Sprachgebiete (Stuttgart 1970); H = Ludwig Hain, Repertorium bibliographicum in quo libri 
omnes ab arte typographica inventa usque ad annum $1500\langle\ldots\rangle$ recensentur, 4 Bde. (Stuttgart u. a. 1826-1838, RP Mailand 1966); HC = Hain und Copinger $(\mathbf{H}$ u. C); IERS = Indice delle edizioni romane a stampa (1467-1500), a cura di P.Lasciano [u. a.]... (Littera Antiqua 1,2, Città del Vaticano 1980); K = Arnold C. Klebs, Incunabula scientifica et medica. Short Title List, in: Osiris 4 (1938) hier 284-286; Kr = Paul Oskar Kristeller, Iter Italicum, 6 Bde. (Leiden u. a. 1965-1997); Pa = Palau (s. o.); $\mathbf{P}=$ L. Polain, Catalogue général des incunables des bibliothèques publiques de France 2 (Paris 1905), 20 (Nendeln 1970); Schrei = Wilhelm Ludwig Schreiber, Handbuch der Holz- und Metallschnitte des XV. Jahrhunderts 10,2 (Stuttgart 31969).

Ergänzungen oder Korrekturen werden im Einzelfall belegt. Verfasser und Titel werden in jedem Block nur einmal am Anfang angegeben; spätere Abweichungen in der Ausführlichkeit der Verfasserbezeichnung oder in der Schreibweise des Titels bleiben im allgemeinen unberücksichtigt.

\section{A. Handschriften}

\section{a. Latein}

1 Rom, Biblioteca Angelica, Cod. lat. 596 (F.6.8)

Papierhs. in Quart $(30 \times 22 \mathrm{~cm})$, zweispaltig, am Anfang beschädigt; undatiert, aber sicher noch aus dem 15. Jh.; wohl nicht das Dedikationsex. für Paul II., aber vielleicht noch vor dem ersten Druck 1468 geschrieben. Die Widmung an den Papst Accipe beatissime pater boc bumane vite speculum... (fol. 87v) ist auch in den Augsburger Druck vom Januar 1471 (s.u. B, a, Nr. 3) übernommen, jedoch nicht die an die Mutter des Verfassers gerichteten Worte Satisfeci iam carissima et pia mater precepto non dixerim voto tuo... (fol. 87r). Ob sie in dem Erstdruck von 1468 (B, a, Nr. 1) Platz fanden, konnte ich noch nicht feststellen.

Beschreibung durch Enrico Narducci, Catalogus codicum manuscriptorum praeter Graecos et Orientales in Bibliotheca Angelica olim coenobii S.Augustini de Urbe (Rom 1893) 253; Hinweise auch bei Laboa, (wie oben Anm. 29) 420 und López Santidrián, (ebd.) 303; Bl 508 Nr. 5879.

Bis auf die Hs. in Salamanca sind alle weiteren vielleicht oder mit Sicherheit Abschriften von Drucken. Die folgende Aufzählung beruht i.d.R. nicht auf Autopsie, sondern auf eingeholten Auskünften oder auf der jeweils angegebenen Literatur, so daß nicht ganz auszuschließen ist, $\mathrm{da} ß$ es sich in einzelnen Fällen gar nicht um Mss. handelt, sondern einen Druck oder Teildruck, der mit Hss. zusammengebunden wurde. Die weitere Reihung erfolgt alphabetisch nach den gegenwärtigen oder zuletzt bekannten Aufbewahrungsorten.

Breslau s. Wroclaw

Danzig s. Gdansk 
2 Gdansk (ehem. Danzig, Stadtbibl.), Ms. Mar. F 171, Misc. fol. 97-163v. 19. Feburar 1479 durch Johannes Rasoris aus Neidenburg (a Jobanne Marci Rasoris de Nydemburgh in civitate Dantzk... feria quinta sive die Jovis decimanona mensis Februarii Anno domini Millesimo-quadringentesimo septuagesimo nono).

Vgl. Otto Günther, Die Handschriften der Kirchenbibliothek von St.Marien in Danzig (Katalog der Danziger Stadtbibliothek 5, Danzig 1921) 156f.; Kr IV (1989) 399b.

3 Hamburg, Staats- und Universitätsbibliothek, Cod. hist. 31e, fol 198v-201v. Bei dem genannten Codex handelt es sich um ein "Historisch-theologisches Kollektaneenbuch des Hieronymus Streitel OESA“, Hauptteil (einschließlich Speculum) geschrieben 1494-1497; vgl. Brigitte Lobse, Die historischen Handschriften der Staats- und Universitätsbibliothek Hamburg. Cod. hist. 1-100 (Katalog der Handschriften der Staats- und Universitätsbibliothek Hamburg 5, Hamburg 1968) 38-44. Lobse 42 verweist für das Speculum auf Hain 13940 (s.u. B, a, Nr. 3). Streitel hat die Widmung an Papst Paul II. sowie die Kapitel von De imperatore bis De exercicio consiliorum (Anfang) übernommen. Kr III (1983) 561a.

4 Krakau, Biblioteka Jagiellonska, 1670. CC VII 26, fol. 1-87;

2. H. 15. Jh. - Nach der Beschreibung in: Wladyslaw Wislocki, Catalogus codicum manuscriptorum bibliotecae Universitatis Jagellonicae Cracovienis 1 (Kraków 1877-1881) 402, beginnt der Text ganz ähnlich wie der Druck bei G. Zainer, Augsburg 1471 (s.u. B, a, Nr. 3), unterscheidet sich aber durch einige Abkürzungen sowie Abweichungen (z.B. statt hispano: Hijspano; Roderico: Radorico; castellano: capedano). Wie in dem genannten Zainerschen Druck lautet auch der Kolophon, jedoch wiederum mit einigen Varianten und vor allem der Änderung am Schluß, statt: Anno a partu virginis salutifero millesimo quadringentesimo septuagesimo primo: ydus vero Januarii tercio, in der Hs.: anno ... septuagesimo quinto. Ein Druck des Speculum durch Zainer im Jahr 1475 ist nicht bekannt. Vermutlich handelt es sich also um eine Abschrift, die 1475 hergestellt wurde. Mit Brief vom 2. Juli 1997 wird diese Vermutung mitgetragen von Marian Zwiercan von der Biblioteka Jagiellonska.

5 Leipzig, Universitätsbibliothek, Cod. 321 (F.p. 117 nr. 9).

Misc.-Hs. 15. Jh., dort als Nr. 6 auf fol. 208-302; soll wörtliche Abschrift des römischen Erstdruckes (s.u. B, a, Nr. 1) sein.

Vgl. Rudolf Helssig, Katalog der lateinischen und deutschen Handschriften der Universitätsbibliothek zu Leipzig. 1. Die theologischen Handschriften 1 (Katalog der Handschriften der Univ.bibl. Leipzig 4,1,1, Leipzig 1926-1935) 455-459, bes. 457; Kr III (1983) 415a.

Leningrad s. St. Petersburg

6 Metz, Bibliothèque Municipale, Nr. 148.

Sammelband des 15. Jh. mit sechs Titeln, hier Nr. 5. - Am Ende: Finit feliciter liber excellentissimus Speculum humane vite nuncupatus, scriptus per manus fratris Joh. Perrini, domus S.Trin.Met. ministri, anno Domini M.CCCC.III- 
Ixx. XVI, die vero $X V$ mensis aprilis, anno vero sue administrationis primo, etatis sue anno liio. [15. April 1496].

Vgl. Catalogue général des Manuscrits des Bibliothèques Publiques des Departments 5. Metz - Verdun - Charleville (Paris 1879, ND Farnborough 1968) 64 f.; Laboa, (wie oben Anm. 29) 421 Nr. 20; López Santidrián, (ebd.) 303.

7 Nürnberg, Stadtbibliothek, Cent. V, 90.

Sammelhs. des 15. Jh. aus dem Nürnberger Predigerkloster; fol. 225r-227r: Rodericus Episcopus Zamorensis. Ex speculo humane vite... libro primo capitulum 38. Particulariter de prima sciencia mathematica videlicet de astronomia.

Ausführliche Beschreibung der ganzen Hs. in: Die Handschriften der Stadtbibliothek Nürnberg 4. Die lateinischen mittelalterlichen Handschriften. Varia 13.-15. und 16.-18. Jahrhundert, bearb. von Ingeborg Neske (Wiesbaden 1997) 111-114. Für Zusendung der Druckfahnen danke ich der Bearbeiterin; Kr III (1983) 666a.

(Oxford, Merton College, Nr. 204, fol. 2r-178v.

Enthält keinen Text von Arévalo. Die Vermutung von Grabes, (wie oben Anm. 41) 275 ist unbegründet; vgl. die Beschreibung der Sammelhs. durch Henry O. Cox, Catalogus Codicum mss. collegii Mertonensis (Catalogue of the Manuscripts of the Oxford Colleges 1, Oxford 1852, ND Oxford 1972) $79 \mathrm{f}$., wo es heißt „Liber qui dicitur speculum vitae humanae auctore anonymo in partes quinque distributus...", das angegebene Incipit nicht mit dem Speculum des Spaniers übereinstimmt und vor allem als Jahr der Niederschrift 1449 angegeben wird.)

Rom. s. Nr. 1.

8 Prag, Knihovna Metropolitne Kapitoly, D 78. Papierhs., 15. Jh.; fol. 1a - 118b; fol. 1a: Incipit humane vite speculum ad bonorem Pauli pape editum... Sanctissimo ac clementissimo in Christo dno dno Paulo secundo... .

Vgl. Ad. Patera, Ant. Podlaba, Soupis Rukopisu Knihovny Metropolitní Kapitoly Prazske 1 (Prag 1910) 385 Nr. 644; Bl 508 Nr. 5879.

9 Salamanca, Biblioteca Universitaria, Nr. 2400.

15. Jh.; vielleicht zeitgleich mit dem röm. Erstdruck, mit dem sie übereinstimmt. Beschreibung durch Florencio Marcos Rodriguez, Los manuscritos pretridentinos de ciencias sagradas en la Biblioteca Universitaria de Salamanca, in: Repertorio de Historia de las ciencias ecclesiasticas en Espana 2 (Salamanca 1971) 259-507, hier $443 \mathrm{f}$.

Kr IV (1989) 602.

10 Salamanca, wie 9, aber Nr. 2460.

Wegen der verschiedenen Nummern und Signaturen wohl nicht mit 9 identisch.Kr IV (1989) 602.

11 St. Petersburg (ehem. Leningrad), Publicnaja biblioteca im M.E. SaltykowaScedrína, Nr. 357. 
Kr V (1990) $179 a$ - dort mit einem Asterix versehen, die Hs. gilt also als verloren.

12 Stockholm, Kungliga Biblioteket, A 237. 15. Jh.

$\mathrm{Kr}$ V (1990) 7a.

13 Wien, Dominikanerkloster, Cod. 26/26.

Misc. XV., Papier, fol. 25v-149v.

Vgl. Felix Czeike, Verzeichnis der Handschriften des Dominikanerkonventes in Wien bis zum Ende des 16. Jahrhunderts (Wien 1952) $27 \mathrm{f}$.

Kr III (1983) 52b, mit Datierung zu 1470/71; Bl 508 Nr. 5879.

14 Wien, Nationalbibliothek, Cod. 3708 (Sammelhs. des 15. Jhs.), fol. 214v-281r. Vgl. Tabula codicum manu scriptorum praeter Graecos et Orientales in bibliotheca Palatina Vindobonensi asservatorum 3 u. 4 (Wien 1864-1868, ND Graz 1965) 60 Nr. 3708; Bl 5879.

15 Wroclaw (ehem. Breslau), Biblioteka Uniwersytecka, IV F 54 misc. $\mathrm{Kr}$ IV (1989) 425a.

16 Wroclaw, wie 15, aber IV F 55.

17 Wroclaw, wie 15, aber IV F 56.

\section{b. Deutsch}

1 München, Bayerische Staatsbibliothek, cgm 1137, fol. 265r-362r (nach Dicke (s.u.) korrekt: 269-366). 15. Jan. 1473 bzw. 19. März 1474. Heinrich Steinböwel: Spiegel des menschlichen Lebens (Autograph). (...spiegel des menschlichen lebens von dem hochwirdigen Rodorico von Hispania bischoffen Zamorensi... per Hainricum Stainhö̈wel doctorem).

Ausführliche Beschreibung durch Borvitz, (wie Anhang 2, Anm. 1) bes. 6-20; knapper bei Karin Schneider, Die deutschen Handschriften der Bayerischen Staatsbibliothek München. Die mittelalterlichen Handschriften aus cgm 8884000 (Catal. cod. scr. Bibl. Mon. 5,6, Wiesbaden 1991) 153; zuletzt Dicke, (wie Anhang 2, Anm. 7) 445-447; vgl. auch Anhang 2.

Mikrofilm/Kopie in meinem Besitz.

2 Regensburg, Staatliche Bibliothek, [noch ohne eigene Signatur] angebunden an $2^{\circ}$ Inc. 272 (d.i.: Robertus Caracciolus, Sermones quadragesimales de poenitentia, Straßburg [Martin Schott], 3. Sept. 1485 (GW 6078)).

137 Blätter (290 x $202 \mathrm{~mm})$; letztes Drittel 15. Jh. - Entdeckt und knapp unter Wiedergabe der lateinischen Widmungsadresse und zweier deutscher Strophen (fol. 136vb - 137ra) beschrieben durch Nikolaus Henkel, Ein neues Übersetzungswerk des deutschen Frühhumanismus. Eine bislang unbekannte Übersetzung der Ständelehre "Speculum vitae humanae“ („Spiegel des menschlichen Lebens") des Rodrigo Sanchez de Arevalo ins Deutsche, verfaßt von Johannes Krachenberger, Sekretär Kaiser Maximilians I., in: ders. (Hrsg.), Bücherschätze in Regensburg. Frühe Drucke aus den Beständen der Staatlichen Bibliothek. Katalog zur Ausstellung in der Staatlichen Bibliothek Regensburg vom 8.2.-2.3.1996 (Regensburg 1996) 39f. 
Aus der Widmungsadresse (fol. 136vb):... Lingwa Rodorici latina scriptitans oda / Humani moris[!] speculum titulum vocitarat / Johannes bumili eloquio de monte crepenti / Tentiuat...

Die beiden deutschen Strophen (fol. 137ra): Senfft gebet / di an mich tet / der hochgelerte man / vom Dorn Christoff / zu dem ich hoff / vnd seiner gunst getrawen han. / An schaw des manns / hab ich Hanns / vom Krachen perg, I twerg der Kunst, / gunst vnd bele prunst / ze werben mich genomen an. Rodorici puech / mit arbait ruech / des lebens spiegel genant / dem er bat / mit pluemen wat / lateinisch seinen standt / hab ich nw pracht / in teutsche achtt / und mueterliche zung. / twung dich guet. / deins gemuet / und er[e]n pluet / herr das mir dein gnad naigen sannt.

Zum möglichen Autor vgl. unten Anhang 2 am Ende.

\section{c. Spanisch (Kastilisch)}

1 Città del Vaticano, Biblioteca Apostolica Vaticana, Vat. lat. 4800.

Vollendet 20. Sept. 1498; Espejo de la vida humana; von mir vor Jahren dem ungedruckten Katalog in der Biblioteca Apostolica entnommen, aber leider nicht eingesehen. Keine Hinweise bei Kroder bei Laboa u. Trame, (wie oben Anm. 29), sowie bei John Richard Law, El ,Spejo dela vida humana' de Rodrigo Sanchez de Arevalo (1404-1470). Estudio y edicion critica [spanish Text] (The Univ. of Texas at Austin, Ph.D. 1980; Univ. Microfilms international, London WCIR 4 EJ 1980). Aber schon bei dem 1684 gestorbenen Antonius (d.i. Nicolás Antonio), Bibliotheca Hispana vetus, 2 (Madrid 1788, ND Turin 1963) 300 wird auf den Codex Ms. 4800 hingewiesen. Nach den Angaben bei Antonius ist der Anfang - bis auf kleine Schreibabweichungen - identisch mit dem Druck von 1491 (s.u. B, c, Nr.1). Am Ende steht: Acabòse el excelente libro intitulado Espejo de la vida humana, escrito por mi el bachiller Francisco de Arce en la muy noble ciudad de Toledo. Acabòse de escribir vispera de S.Matheo Apostol 20. de Setiembre ano del nacimiento de nuestro Salvador Jesu Christo de MCDXCVIII. años. Der von Antonius geäußerte Verdacht, der spanische Druck von angeblich 1491 sei gar nicht so alt, weil die Hs. von 1498 utique post editionem frustra fuisset, wird durch die lateinischen Handschriften, für die ähnliches gelten müßte, entkräftet.

\section{B. Drucke vor 1500}

\section{a. Latein}

1 Rodoricus Episcopus Zamorensis: Speculum vite humane. Rom: Conrad Sweynheym und Arnold Pannartz, 1468. $2^{\circ}$.

Am R-214, Bl 5879, HC *13939, IERS 9, K 857.1, Law 1, P 10423 u. 10424 (10.184), Pa 272017, Toni 1. 
Abb. der im oberen Teil handschriftlichen (!) Titelblätter der Exemplare in der Library of Congress und The Royal Library, Windsor Castle bei Goff, (wie oben Anm. 27) 82 u. 83; das. 84f. Auflistung von 55 gegenwärtigen Besitznachweisen. Zu den beiden Druckern vgl. mit weiteren Literaturangaben $A r-$ nold Esch, Deutsche Frühdrucker in Rom, in: Gutenberg-Jb. (1993) 44-52, hier $48 \mathrm{f}$.

[Köln 1468/70 bzw. 1469.

Erwähnt bei Keniston, (wie oben Anm. 37 Nr. 1) 193, Pa S. 178 ohne Nr.; s.u. Nr. 6]

2 [Rom: Georg Lauer, 1470]. $2^{\circ}$.

C 5137, H 13934, K 857.2, Law 10, Toni 2, nicht im IERS!

[Sevilla: Christopherus Beyamus, 1470?

HC 13937, Law 11, Toni 15; wohl Verwechslung mit Nr. 10; aber auch Dietrich Reichling, Appendices ad Hainii-Copingeri Repertorium bibliographicum. Additiones et emendationes, 6 (München 1910) 138 datiert zu (1470)]

3 Augsburg: Günther Zainer. III. Id. Ianuarii [11. Januar] 1471. $2^{\circ}$.

Am R-215, Bl 5879, HC *13940, K 857.3, Law 2, P 10425 (10.185), Pa 2720218, Toni 3.

Von mir benutztes Exemplar: Berlin SBBPK, Inc. 6 (ehem. Duplum Bibliothecae Regiae Monacensis).

Augsburg: Zainer. 1472Pa 272020 (keine weiteren Nachweise).

4 [Paris: Ulrich Gering, Michel Friburger und Martin Crantz, nicht nach 22.4. 1472]. $2^{\circ}$.

Am R-216, Bl 5879, C 5138, H 13935, K 857.5 u. 5var, Law 12, P 10420 (10.181), Toni 14.

Datum erschlossen durch eine Widmung in Form eines gedruckten Briefes an Ludwig XI. in einigen Ausgaben: genauer bei G II,190. Da Gering Gehilfe des Helyas Helye in Beromünster war, bleibt noch zu klären, ob sein erster Pariser Druck Pläne des Helyas vorweg realisierte oder ob der Meister sich von seinem ehemaligen Gehilfen anregen ließ; vgl. Nr. 5.

5 Beromünster: Helias Heliae de Louffen. Vigilia conceptionis Mariae [7.XII.] 1472. $2^{\circ}$.

Am R-217, G I, 185 f., HC 13941, K 857.6, Law 3, P 10426 (10.186), Pa 272021. $\mathrm{Zu}$ dem Beromünster Chorherrn Helyas Helye vgl. auch Joseph Frey, Die firmierten Beromünster Drucke, literärgeschichtlich betrachtet, in: GutenbergJb. (1961) 40-42, mit Hinweis auf Josef Ludwig Aebi, Die Buchdruckerei zu Beromünster im 15. Jahrhundert. Eine Festschrift zur Jubelfeier im Jahr 1870 (Einsiedeln 1870).

6 [Köln: Ulrich Zell, 1472]. $4^{\circ}$.

Am R-218, HC *13933, K 857.4, Law 13, P 10414 (10.176 b) (zu c. 1470).

Die von Keniston, (wie oben Anm. 37 Nr. 1) 193 zitierte Ed. of Cologne [1469], f.[3]v ist wohl mit diesem Druck gemeint.

7 Beromünster: Helias Heliae de Louffen. Feria sexta post festum beate Jacobi 
apostoli [30. Juli] $1473.2^{\circ}$.

Am R-219, Frey (wie Nr. 5), G I, 185 f., HC *13942, K 857.8, Law 4, P 10427 (10.187).

8 Rom: Johannes Philippus de Lignamine, 31. Juli 1473. $2^{\circ}$.

Am R-220, HC 13943, IERS 199, K 857.9, Law 5, P 10428 (10.188), Pa 272022, Toni 6.

[Augsburg: Günther Zainer 1473. $2^{\circ}$. So Georg Wilhelm Zapf, Augsburgs Buchdruckergeschichte 1 (Augsburg 1788; ND Leipzig 1968) 24; vermutlich Verwechslung mit Nr. 3]

9 Paris: Pierre César und Jean Stol [1473]. $2^{\circ}$. Am R-221, Bl 5879, HC 13938, K 857.7, P 10418 (10.179) (zu 1474?) u. P 10419 (10.179), Pa 272024.

Vgl. auch Jeanne Veyrin-Forrer, Le deuxième atelier typographique de Paris: Cesaris et Stol, in: Gutenberg-Jb. (1976) 117-129, hier 126 Nr. 7.

10 [Savigliano:] Christophorus Beyamus [und Johannes Glim 1473-74]. $4^{\circ}$.

Am R-222 (nennt J. Glim als zweiten Drucker), Bl 5879 (zu 1471[!]), G II,161 (im Druck „nur Beyamus genannt"), HC und Reichling (wie nach Nr. 2) 13937, K 857.10, P 10421 (10.182) (zu c. 1471), Pa 272019. - Savigliano liegt im Piemont und sollte nicht mit Sevilla verwechselt werden.

11 Paris: Ulrich Gering, Michel Friburger und Martin Crantz, 1. August 1475. $2^{\circ}$. Am R-223, HC 13945, K 857.11, Law 7, P 10429 (10.189), Pa 272025, Toni 10.

12 Basel: Martin Flach, 28. November 1475. $2^{\circ}$.

Am R-224, G I,117, HC 13944, K 857.12, Law 6, P 10430 (10.190), Pa S. 179 (zu Straßburg), Toni 9.

[Augsburg: Günther Zainer, 1475. - Zu dieser Angabe s.o. A, a, Nr. 4.]

13 Lyon: Guillaume Le Roy für Barthélémy Buyer, 7. Januar 1477. $2^{\circ}$.

Am R-225, H 13946, K 857.14, P 10431 (10.191), Pa 272026.

[Law 8 „Londres, Guillermus Regis... 1477" offenbar irrig statt wie Nr. 13]

14 [Paris: Au Soufflet Vert (Louis Symonel et Socii) um 1477]. $4^{\circ}$ und $8^{\circ}$.

Am R-226, HC 13936, K 857.13, P 10415 (10.177), 10416 (10.178) u. 10417 (10.178c).

15 [Toulouse: Johann Parix u. St. Cleblat 1479-81]. $2^{\circ}$.

Am R-227, G II,239ff.(241 Abb. 96: fol. 1, um 1480), K 875.15, P 10422 (10.183), Pa 272027 (zu c. 1480).

Vgl. auch Antonio Odriozola, Los protoincunables (1472-1479) impresos por Juan Parix en Segovia (España) y Toulouse (Francia), in: Gutenberg-Jb. (1976) 130-137, hier $135 \mathrm{f}$. Nr. 9.

16 Loewen: Johann von Paderborn [um 1480]. $2^{\circ}$.

Als fünftes Stück einer Sammlung mehrerer Traktate, angeführt von: Butrio, Antonius de, Speculum de confessione.

C 1397, Gesamtkatalog der Wiegendrucke (GW), hrsg. von der Kommission für den Gesamtkat. d. Wiegendrucke. Bisher 9 Bde. (Stuttgart 21968-90) 5.5829; vgl. auch P 3125 (305).

17 Loewen: Johann von Paderborn [nicht vor 1483]. $2^{\circ}$. 
Wie Nr. 16, aber deutlich andere Druckfassung.

HC 4185, GW (s.Nr. 16) 5.5830, P 3126 (306).

[[Basel:] M.Flach, 1485.

Vgl. Carlos Gilly, Spanien und der Basler Buchdruck bis 1600 (Basler Beitr. z. Gesch.wiss. 151, Basel, Frankfurt a.M. 1985) 496 Nr. 601; offenbar Verwechslung mit Nr. 12.]

18 Besançon: [Peter Metlinger] 1488. $4^{\circ}$.

Daran: Speculum conversionis peccatorum; Speculum sacerdotum; Speculum ecclesie; Speculum animae peccatricis; Tractatus de horis dicendis; De casibus penitentialibus; De arte bene moriendi.

Am R-228, G II,247 (Abb. 99: fol. b 3r), H 13947, K 857.16, P 10434 (10.192e), vielleicht identisch mit H 13946 u. P 10432 (10.192), Pa 272028.

[Strassburg: Johannes Prüss, pridie Idus Jann. 1495.

Aus ungedr. Katal. des GW unter Hinweis auf Faenza, Biblioteca Comunale, jedoch mündlich am 3.6. 97 nicht bestätigt; sicher Verwechslung mit Straßburg 1507 Jan. 12 (Pridie Idus Ianuarii), vgl. C, a, Nr. 1]

\section{b. Deutsch}

1 Rodoricus Zamorensis: Spiegel des menschlichen Lebens. (fol. 1r: Dises buechlin genannt der spiegel des menschlichen lebens von ... Rodorico von byspania, byschoffen Zamorensi gemachet...). Übers. Heinrich Steinhöwel [Augsburg: Günther Zainer], 1475 nach März 26. $2^{\circ}$.

Am R-231, H *13948, K 858.1, Law 17, P 10437 (10.195), Pa 272037, Schrei 5102, Toni 17.

Die Datierung ergibt sich aus einer Bemerkung Steinhöwels am Ende seines Widmungsvorwortes für Herzog Sigismund, wo er dessen Stammbaumabbildung interpretiert und sich bei der Erwähnung von Maximilians Tauftag Ostern (d.i. 25. März) 1459 - bewußt wird, daß es gerade wieder Ostern ist, und zwar 1475 (d.i. 26. März), als Steinhöwel in Dillingen beim Augsburger Bischof weilte: $X X$ Maximilianus des egenantten kayser fridrichs liebster sun. vnnd ist geborn Anno domini MCCCCLIX. an dem gruendormstag ond getaufft an dem ostertage buot auff disen tag oster aubet. Anno domini $M C C C C L X X V$. zu Tilingen bey dem Erwirdigsten $N$. byschoff ze augspurg. Blatt [10v] der ersten zehn im Druck ungezählten Blätter, auf die dann mit c. 1 des Spiegels die Blattzählung (I-CLXIIII) folgt; vgl. auch Borvitz (wie Anhang 2 Anm. 1) 19. Zu den 57 Holzschnitten s. unten Anhang 3. -

Ich zitiere nach dem Berliner Exemplar SBBPK Inc.46 (dort im Einband von der Hand eines Bibliothekars: $H * 13948$ abweichend). Auf mehreren Seiten z. B. *1r, 16v, 25r, 36r u.ö. handschriftlicher Besitzeintrag: Iste liber est Monasterii Benedictenpewren. Vor einer definitiven druckgeschichtlichen Zuordnung dieses Exemplars ist noch eine Reihe von Fragen zu lösen. Der Lautstand und die Orthograhie weichen recht erheblich von dem Autograph Steinhöwels $a b$, so daß keineswegs gesichert ist, daß das Autograph die Vorlage für den 
Erstdruck gewesen ist (so zuletzt G.Dicke im Verf.Lex. 9 (München 1995) $269 \mathrm{ff}$.). Gelegentlich ist der Druck von alter, offenbar bayerischer Hand korrigiert oder ergänzt, wobei es ganz unwahrscheinlich ist, daß das Autograph zu Rate gezogen wurde, aber auch Nr. 4 (Berger) kann dem Korrektor nicht vorgelegen haben. Diese Feststellungen sowie die Bemerkungen zu den Drukken 3 und 4 bedeuten für die Steinhöwel-Philologie, daß eigentlich nur sein Autograph als zuverlässige Basis angesehen werden kann.

2 Wie 1.

Bei dieser zweiten, weniger seltenen Ausgabe fehlt der Holzschnitt eines die Wappen Tyrol, Alt-Oesterreich, Oesterreich, Schotten tragenden wilden Mannes auf fol. 1r, vgl. Weil, (wie Anhang 3, Anm. 6) 107. Wird in den meisten Verzeichnissen nicht gesondert gezählt.

3 Augsburg: Johann Bämler, Freitag nach Magdalenentag [23. Juli] 1479. $2^{\circ}$. Am R-232, H *13949, K 858.2, Law 18, P 10438 (10.196), Pa ohne Nr. nach 272037, Schrei 5103, Toni 18. Schon aufgrund der Teilreproduktion von $1908-$ vgl. unten C, b, Nr. 1 - läßt sich feststellen, daß Bämler zwar für seine $54 \mathrm{Ab}$ bildungen die Holzstöcke von Zainer übernommen, aber sonst erhebliche Kürzungen durchgeführt hat. Es fehlen nicht nur die Widmungen an Papst Paul II. und Sigismund von Österreich, sondern auch die Kapitelüberschriften im Register und im Text sind von 3-6 Zeilen auf je eine Zeile gekürzt. Im ersten Buch scheint c. 24 ausgelassen zu sein, so daß c. 25 bei Zainer c. 24 bei Bämler wurde. Entsprechendes gilt für c. 29 und c. 37 sowie c. $41-43$ bei Zainer. Im zweiten Teil fehlen die c. 5-7, 20 und 22-30. Dagegen fallen Abweichungen in der Schreibweise (z. B. im Titelblatt Zainer: staut.. stäten - Bämler: stätten.. stätten - gemeint sind: Stände -) weniger ins Gewicht.

Zu Bämler vgl. G I,138 mit weiteren Literaturhinweisen.

4 Augsburg: Peter Berger, St. Bartholomäus Abend [23. August] 1488. $2^{\circ}$.

Am R-233, G I,157, H *13950, K 858.3, Law 19, Pa ohne Nr. nach 272037, Schrei 5104, Toni 19.

Ich benutzte das Exemplar der Bayerischen Staatsbibliothek München $2^{\circ}$ Inc. ca 2103 mit dem Titelblatt: Speculum humane vite. Der menschen Spiegel.

Der Druck von Berger unterscheidet sich nicht unwesentlich von dem durch Zainer. Er verwendet nicht nur andere Drucktypen, sondern bietet oft eine andere Rechtschreibung, insbesondere bei den Vokalen (z. B. zwai statt czwey); zudem wird der Text gelegentlich gekürzt, gelegentlich auch sinnwidrig verändert (z. B. wirdigkeit statt widerwärtigkait, fol. 1r). Die meisten Holzschnitte erscheinen gegenüber dem Erstdruck seitenverkehrt bzw. spiegelbildlich, einige sind nur vergröbernde Nachahmungen (z.B. auf fol. $62 \mathrm{r}$ die Abb. zur Theatrica im Vergleich zu fol. 66v bei Zainer). Die echten Stöcke waren ja auch schon 1482 in Lyon in den Händen von Philippi und Reinhard, s.u. d, Nr. 3. 


\section{c. Spanisch (Kastilisch)}

[Zaragoza: Paul Hurus, 13. Mai 1481.

Francisco Vindel, El arte tipografico en España durante el siglo XV. 4: Zaragoza (Madrid 1949) 33 Nr. 12 bemerkt zu Recht, daß eine in manchen Bibliographien - z. B. bei Conrad Haebler, Bibliografía ibérica del siglo XV. 2 (Leipzig, Den Haag 1917) Nr. 578 - schon zu 1481 notierte Edition nicht nachweisbar ist und auf der Verwechslung mit der Ausgabe von 1491 beruht.]

1 Rodericus Zamorensis: Spejo dela vida humana. Zaragoza: Paul Hurus, 13. Mai $1491.2^{\circ}$.

Am R-234, C 5140, G II,273ff., H 13954, K 860.1, Law 24, Pa 272040, Toni 24.

Vgl. Martin Kurz, Handbuch der iberischen Bilddrucke des 15. Jahrhunderts (Leipzig 1931) und Dietrich Briesemeister, Die deutschen Frühdrucker in Spanien, in: Gutenberg-Jb. (1993) 53-61, hier 56f.; vgl. auch Vindel, (wie eben) 123-132 Nr. 42, dort 124 Abb. der Prologseite (a II) und 125 Abb. der letzten Seite (95) mit dem Druckervermerk, 126-132 Abb. der 39 Holzschnitte; Haebler, (wie eben) Nr. 579.

Die 39 Holzschnitte stammen höchstwahrscheinlich von den ehemals Zainerschen Stöcken, die zwischenzeitlich von Bämler (1479) und sodann (1482) in Lyon genutzt wurden. Dabei fällt auf, daß z.B. der Holzschnitt zum Thema Theatrica nicht verwendet wurde und an seiner Stelle der Holzschnitt zu c. 5 (bei Zainer fol. 13v) nun zu c. 31 gestellt wurde (fol. [8]v).

2 Zaragoza: Paul Hurus, 13. Mai $1491.2^{\circ}$ wie Nr. 1; die Exx. unterscheiden sich durch Druckermarken; vgl. die bei 1 angegebene Literatur.

\section{d. Französisch}

1 Roderique hispagnol euesque de Zamorensis: Le miroir de la vie humaine. Übers. Fr. Julien Macho. Lyon [Guillaume Le Roy für] Barthélémy Buyer, 8. Juli $1477.2^{\circ}$.

Am R-229, HC $* 13951, \mathrm{~K}$ 859.1, Law 20, P 10435 (10.193), Pa 272038, Toni 20.

2 Übers. Fr. Julien Macho. Lyon: Barthélémy Buyer 1479. $2^{\circ}$. $\mathrm{H} * 13952$, Law 21, nicht bei $\mathrm{P}$ und $\mathrm{Pa}$, Toni 20 (irrig statt 21).

3 Übers. Pierre Farget. [Lyon:] Nicolaus Philippi und Marcus Reinhard, 20. August $1482.2^{\circ}$.

Am R-230 (gibt ebf. Macho als Übers. an), HC 13953, K 859.2, Law 22 (zu Straßburg), P 10436 (10.195), Pa 272039 (Traducción anónima), Toni 22.

Nach G II 210 sind die Holzschnitte vorher von Günther Zainer in Augsburg (s. B, b, Nr. 1) benützt. Philippi und Reinhard werden sie von Bämler übernommen haben.

[Toulouse 1480.

Law 23, Toni 23: Verwechslung mit B, a, Nr. 15] 


\section{Drucke nach 1500}

\section{a. Lateinisch}

Von den neueren gedruckten Bibliothekskatalogen wurde zusätzlich herangezogen: Bayerische Staatsbibliothek. Alphabetischer Katalog 1501-1840. VorausAusgabe 44 (München u. a. 1990) 183; abgekürzt: Mü.

1 Straßburg: Johannes Prüß, 11. Januar 1507. Mit Beiträgen von Johannes von Botzheim, Paul Burger, Sebastian Brant, Jakob Wimpheling, Matthias Ringmann, Johannes Gallinarius, Symphorian Altbiesser, Beatus Rhenanus, Beatus Arnoldus, Johannes Castmeister.

Law 25, Pa 272029, Charles Schmitt, Répertoire bibliographique Strasbourgeois jusque vers 1530. 3: Jean Prüss, Père e fils (Straßburg 1893) 17 Nr. 59, Toni 25 , Wilhelmi, Brant-Bibliographie (wie oben Anm. 24) 184 Nr. 561, VD (= Verz. d. i. dtsch. Sprachbereich ersch. Drucke d. 16. Jhs., Hg. Staatsbibl. München u. Herzog-August-Bibl. Wolfenbüttel (Stuttgart 1991) 16, Abt. I,17, R 2700, Mü.

Wie 1, aber „en folio de pergamino“, so unter Hinweis auf ,Biblioteca National de Madrid y Archivo Boncompagni de Roma' Law 26; Toni 26.

Lyon: Johannes Prüß, 1507; so C. Gilly (wie oben B, a nach Nr. 17) 112. Wahrscheinlich hat G. hier Lyon mit Straßburg verwechselt.

2 Paris: Jean Petit, Philippe Pigouchet, 31. Okt. 1510,

Pa 272030, Mü; vgl. Brigitte Moreau... d'après les manuscrit de Philippe Renouard, Inventaire chronologique des éditions parisiennes du XVIe siècle, 1. 1501-1520 (Paris 1972) 384 Nr. 188 (mit Hinweisen auf die Beiträge wie in Nr. 1).

Paris: Jean Petit, 1510.

$\mathrm{Pa}$ im Anschluß an 272030 ohne eigene Zählung verweist auf das Brit. Museum: „P. Pigouchet, impensis I. Parui: in Parrhisiorum academia, 1510, 80“. Da seine Nr. 272030 eine Quartausgabe meint, könnte hier also ein weiterer Druck vorliegen.

3 Venedig: Lazarus de Soardis, 19. Januar 1513. $\mathrm{Pa} 272031$, Mü.

4 Lyon: Simon Benelague (oder Bene Lagua), 2. Mai 1516. Law 27 (Londres!), Pa 272032, Toni 27, Mü.

5 Paris: Jean Petit, 1522.

Pa ohne eigene Nr. nach Nr. 272032; vgl. Moreau, (wie Nr. 2) 3. 1521-1530 (Abbeville 1985) 150 Nr. 398.

6 Paris: Galeotus Pratensis, 1542. Law 28, $\mathrm{Pa} 272033$, Toni 28.

7 Paris: Galeotus Pratensis, 1544. Law 29, Toni 29. 
8 Brescia: Francisc. u. Petr. Mariani Fratres de Marchettis, Vincent. Sabiens. 1570.

Law 31 (mit ?), Pa 272034, Toni 31, Mü.

9 Basel: [?], 1575.

Law 30, Toni 30.

10 München: Adam Berg, 1590.

Jodocus Lorichius: Specvli vitae hvmanae sinopsis. Ex tractatu R. quondam Domini Roderici, Zamorensis et Calagaritani Episcopi, de eodem argumento perscripto.

Toni Anm. zu 31 (S. 359), aber zu 1589; besser VD 16,1 (wie oben bei Nr. 1) 11 (Stuttgart 1987) L 2548.

Hannover: Melchior Goldast, 1603.

DHGE 3 (1924) 1659, vielleicht verwechselt mit Nr. 12.

11 Straßburg: Lazarus Zetzner, 1606.

C. Gilly (wie oben B, a, nach Nr. 17) 112; Law 32, Toni 32, Mü. - Merkwürdigerweise ist dieser Druck ebensowenig wie die Nr. 13 berücksichtigt bei Jacques Betz, Repertoire bibliographique des livres imprimés en France au XVIIe siècle. 7. Alsace (Bibliotheca bibliographica Aureliana 102, BadenBaden 1984).

12 Hanau: Heredes Joan. Aubrii, 1613.

Law 33, Pa 272035, Toni 33, Mü.

13 Straßburg: Lazarus Zetzner, 1616.

Law 35 (wohl identisch mit Law 34), Toni 35.

14 Paris: M. Soly, 1656.

Law 37, Toni 37, Mü.

15 Paris: Thiery, 1663.

Law 36, Toni 36.

16 Frankfurt: J. Andres, 1683.

DHGE 3 (1924) 1659, Law 38, Pa 272036, Toni 38, Mü.

\section{b. Deutsch}

1 Nach den beiden Zainerschen Drucken von 1475 und den Drucken bei Bämler (1479) und Berger (1488) und der Weitergabe der Holzschnittstöcke, die 1491 bei Hurus in Zaragoza landeten, ist Arèvalos Ständespiegel für den deutschlesenden Kunden nicht mehr aufgelegt worden. Es erschien lediglich ein 64 Seiten starker Auszug in Faksimile-Druck der Bämlerschen Ausgabe, dessen Anliegen es offenbar gewesen ist, die 54 Abbildungen zu präsentieren, - herausgegeben von der Graph.-Kunst-Anstalt Hubert Köhler, München 1908.

\section{c. Spanisch (Kastilisch)}

1 Die kastilische Fassung des Speculum ist nach dem Druck durch Hurus (1491) nicht wieder auf dem Büchermarkt erschienen, bis 1980 John Richard Law 
seine kritische Edition anbot (wie oben Anlage 1, A, c, Nr. 1; Law 136-635). Der Edition sind zwar eine linguistische Analyse und eine Inhaltsangabe vorangestellt, doch ist die Textwiedergabe ohne Anmerkungen, so daß sich das ,Kritische' auf die Auflösung der Abbreviaturen in der Ausgabe von 1491 beschränkt. 


\section{Anhang 2}

\section{Übersetzung und Ergänzung des Speculum durch Heinrich Steinhöwel}

Die Übersetzung des Speculum aus dem Lateinischen ins Deutsche ist bereits 1914 monographisch auf mehr als 150 Seiten untersucht worden ${ }^{1}$. Mithin liegen ausreichende, wenn auch gelegentlich ergänzungsbedürftige Informationen vor über das heute noch einsehbare, den ersten Teil am 15. Januar 1473 und den zweiten am 19. März 1474 beendete Autograph ${ }^{2}$ des in Weil der Stadt (in der Nähe von Calw) 1412 geborenen und höchstwahrscheinlich am 1. März 1479 als Stadtarzt von Ulm gestorbenen, auch sonst als, von Sinn zu Sinn' mannigfach tätigen und anerkannten Übersetzers Heinrich Steinhöwel ${ }^{3}$, über seine Vorlage, den Augsburger Druck von $1471^{4}$, über die dem Korrektor oder Drucker in der Günther Zainerschen Offizin zu Augsburg anzulastenden Abweichungen vom Autograph in der ersten Auflage vom Jahr $1475^{5}$, besonders sodann über Stil und Grammatik und schließlich über Kürzungen, Erweiterungen sowie falsche und schiefe Übersetzungen. An dieser Stelle sollen lediglich die den bantkunsten bzw. dem bantwerck oder

1 Walther Borvitz, Die Übersetzungstechnik Heinrich Steinhöwels. Dargestellt aufgrund seiner Verdeutschung des „Speculum vitae humanae“ von Rodericus Zamorensis. Eine stilistische Untersuchung (Hermaea 13, Halle 1914).

2 S.o. Anhang 1, A, b, Nr. 1. - Auf die eigenhändigen Datierungsangaben Steinhöwels (fol. 324v bzw. 362r) verweist bereits Borvitz, (wie Anm. 1) 14; Faksimile der Datumsangabe von 1474 bei Sudhoff, (wie Anm. 8) 170.

$3 \mathrm{Zu}$ Leben und Werk vgl. außer Borvitz, (wie Anm. 1) Ursula Hess, Heinrich Steinhöwels ,Griseldis'. Studien zur Text- und Überlieferungsgeschichte einer frühhumanistischen Prosanovelle (MTU 43, München 1975) und Irene Hänsch, Heinrich Steinhöwels Übersetzungskommentare in „De claris mulieribus“ und „Äsop“. Ein Beitrag zur Geschichte der Übersetzung (Göppinger Arb. z. Germ. 297, Göppingen 1981) sowie die dort angegebene Literatur, bes. Karl Drescher (Hrsg.), Boccaccio de claris mulieribus. Deutsch übersetzt von Stainhöwel (Bibl. Lit. Ver. 205, Tübingen 1895). - Zum historischen Kontext der nur in die ersten Drucke des Spiegels übernommenen Widmung an Sigmunden hertzogen ze österreych vgl. Peter Assion, Der Hof Herzog Siegmunds von Tirol als Zentrum spätmittelalterlicher Fachliteratur, in: Fachprosa-Studien. Beiträge zur mittelalterlichen Wissenschafts- und Geistesgeschichte, hrsg. von Gundolf Keil (Berlin 1982) 37-75. - Zum Sterbedatum wie zum ganzen Leben zuletzt: Gerd Dicke, Neue und alte biographische Bezeugungen Heinrich Steinhöwels. Befunde und Kritik, in: Zs. f. d. A. u. d. Lit. 120 (1991) 156-184; ders., (Art.) Steinhöwel, Heinrich, in: Verf.lex. 9 (1993) 258-278; Nikolaus Henkel, Heinrich Steinhöwel, in: Deutsche Dichter der frühen Neuzeit (1450-1600). Ihr Leben und Werk, hrsg. von Stephan Füssel (Berlin 1993) 5170 (dort 60-62 zum, Spiegel des menschlichen Lebens ${ }^{\circ}$ ).

${ }^{4}$ S.o. Anhang 1, B, a, Nr. 3 .

5 S.o. Anhang 1, B, b, Nr. 1. - Die wenigen von Borvitz, (wie Anm. 1) 20 vermerkten Differenzen von Autograph und Druck lassen sich in einem $M a ß$ vermehren, das fragen läßt, ob tatsächlich die überlieferte Handschrift unmittelbare Vorlage beim unterstellten Druck gewesen ist oder ob nicht doch eine weitere $Z$ wischenstation angenommen werden muß. 
den handtwercken gewidmeten Kapitel auf von Steinhöwel zusätzlich angebotene Informationen befragt werden. Der Ulmer Arzt ist insgesamt redseliger, anschaulicher und differenzierter als der Kastellan der Engelsburg, aber insofern, gerade für den Bereich der ihm selbst näherstehenden und aus eigener Erfahrung besser vertrauten artes mechanicae, mit seinem Spiegel des menschlichen lebens eine über das Speculum vite bumane handwerksgeschichtlich und terminologiehistorisch hinausweisende Quelle. Steinhöwel nutzte in diesem Zusammenhang auch Vorlagen, die Arévalo nicht herangezogen hatte, z.B. Hugo von Trimberg mit seinem Renner ${ }^{6}$ oder die von ihm selbst übersetzten Facetien Poggios ${ }^{7}$. Als Belege mögen einige Beispiele genügen, zumal dieser Beitrag ohnehin keine erschöpfende Analyse Arévalos und Steinhöwels zu sein beansprucht, sondern vornehmlich die Lust auf eigenes Lesen wecken möchte.

Hält sich Arévalo in c. 23 (de artibus mechanicis in genere ...) bei der Aufzählung der Berufe und Tätigkeiten eng an das Didascalicon des Hugo von St. Viktor, so beläßt es Steinhöwel (von den bandtwercken in gemeyn) nicht bei einer an sich schon sprachlich interessanten Verdeutschung, sondern differenziert noch über seine Vorlage hinaus. Lateinische Fassung: Sub lanificio vero plurima vite genera includuntur, puta texendi, torquendi, suendi et que sunt manu, acu, fuso, rota, fibula sive aliis instrumentis et cetera omnia que in materia lana, lino, pelle, pilo et vimibus continentur. Armature vero adoptatur, quisquid armorum est, et quicquid ferro metallisque continetur, sub qua aurifices, metallarii, monetarii ac alchimiste militant. Übersetzung: Aber vnder den wollenwerck werdent manigerley kunsten gebriffen (Autograph richtig: begriffen): weben, kemen (Autograph: kemmen), zaisen, spinnen, neen ond was mit der nadlen (Autograph: nadeln) arbeyt kursener, schneyder, schuchmacher und was mit lein, flachs, wollen, fellen vnd anderer rauber (Autograph: ruber) war vmb gat. Vnder den schmid werck seind alle die mit waffen vmb gand, vnd alle die mit eysen, stahel, kupfer, gold, bley oder andern metallen ire gewerb oder werck treibent, als goldschmied, kantengiesser, mintzmeister, alchimisten vnd ir gleichen.

${ }^{6}$ c. 18 , fol. $35 \mathrm{rv}$, anläßlich der Unterscheidung der guten und schlechten Juristen; vgl. Der Renner von Hugo von Trimberg, hrsg. von Gustav Ehrismann (StLV 247, 248, 252 und 256, Tübingen 1908-1911, ND mit Nachwort und Ergänzungen von Günther Schweikle, 1970/ 71), hier V. 8513-8553. - Borvitz, (wie Anm. 1) 110 zitiert aus dem Autograph und verweist zudem auf eine Erwähnung des Freidank (im 2. Buch c. 2), die aber nicht zu verifizieren ist. 7 c. 28 , fol. 64v, anläßlich der Kritik an übertriebener Jagdleidenschaft, mit Hinweis auf die Unvernunft, untz über die oren zebaden; c. 32, fol. 70r, bei der Kritik an Heilern, die mit einem Rezept alle Krankheiten kurieren wollen, mit Hinweis auf die verlornen esel; vgl. Die Facezien des Florentiners Poggio, eingel. und übers. von Hanns Floerke, (Hanau 1967) 27-30 Nr. 2, Von einem Arzt, der Narren und Irrsinnige heilte, bzw. 116f. Nr. 87, Von einem Kurpfuscher, der Esel wiederverschaffte. - Steinhöwel hat einige Facetien Poggios in seine lateinisch-deutsche Ausgabe des Esopus übernommen; vgl. Esopus, übersetzt von Heinrich Steinhöwel, gedruckt von Günther Zainer in Augsburg um 1477/78. Faksimile (Die Inkunabel in ihren Hauptwerken, Potsdam 1921); Hermann Österley (Hg.), Steinhöwels Äsop (StLV 117, Tübingen 1895); Gerd Dicke, Heinrich Steinhöwels „Esopus“ und seine Fortsetzer. Untersuchungen zu einem Bucherfolg der Frühdruckzeit (MTU 103, Tübingen 1994). 
Etwas später bei der bäuerlichen Tätigkeit wird aus et quisquid ad nemora ac pascua et ortos pertinet in der Übersetzung: Es seie in den ackern, weingarten, baumgarten, krautgarten, zewald oder weyde. Analog wird bei der theatrica, dem freuden spiel, aus histriones, bufones, representatores, tragici: tantzen, reyen, springen, stechen, turnieren, spilleut, gackler (Autograph: gokler), freibeyt, iufer, geogierer (d.i. Herolde und Ausrufer). Über derlei Differenzierungen und Verdeutschungen hinaus mag es für Theaterwissenschaftler und Germanisten bemerkenswert sein, daß Steinhöwel unter den schimpflichen Dingen des Freudenspiels an erster Stelle das osterspil erwähnt sowie Arévalos knappe, auf Isidor von Sevilla und Hugo von St. Viktor verweisende etymologische Deutung der theatrica ... a theatro so ergänzt: Vnnd ist die stat also geordnet gewesen mit sitzen, das alle menschen, alle ding geleich seben möchtent, als diethrichs haus zebern (Autograph: dietrichs hus zebern) inwendig gewesen ist. Die hier am Beispiel von c. 23 registrierte Methode Steinhöwels, durch marginal erscheinende, aber gleichwohl neu wertende und Eigenes hinzufügende Ergänzungen seine Vorlage anzureichern, wird in anderen Abschnitten durch wesentlich längere Einschübe so überdehnt, daß der Übersetzer zum Coautor avanciert. Für die Medizinerpartien ist das schon von Karl Sudhoff bemerkt und dargelegt worden ${ }^{8}$. Für das Handwerk im engeren Sinne ist ein vergleichender Blick in die wollen- und schmid werck-Kapitel (c. 25 und 26) besonders lohnend': Lateinische Fassung in c. 25: .. Quis enim exprimere possit, quot sophisticatas telas conficiunt, quot filorum falsas commixciones adiiciunt, quot furta et rapinas committunt. Texunt plerumque lenes pannos, bona furantes inutilem lanam apponentes, flo pondere librant. Taceo fallacias in filando maleque torquendo, dolos in texendo, falsas adulterinosque colores intigendo. Taceo denique sutorum fraudes ac furta, quia vix nisi ex furto vescuntur. Harum itaque artium fraudes atque miserias sacra scriptura commemorat...

Deutsche Fassung: ... Von erst an der wollen: $O$ wie offt vermischent vnd verwickeln die schäffer vngewaschne klotzete wollen mitteln in die guten schäpper; wie oft verbrennent die kemmer die guten wollen, das sy bert wirt vnd das gewand vngeschlacht. Wie offt seynd die abprech der spinnerin außwendig zart ond wol gespunnen ond inwendig grob als wurst bendel. Wie offt vertreien sy $d z$ garen, dar von blaterte tuch werdent. $O$ wie grossen valsch treibent die marner selber, so sy ettlich eln, doch wenig wol ond dick webent ond bereytent czu dem schaw falt, den man außwendig seben mag, ond das ubrig inwendig verborgen, als die reitern ge-

8 Karl Sudhoff, Der Ulmer Stadtarzt und Pestschriftsteller Doctor Heinrich Steinhöwel, in: Die ersten gedruckten Pestschriften, hrsg. von Arnold C. Klebs, Karl Sudhoff (München 1926) 169-224, bes. 182, ebd. 187-190 Wiedergabe von c. 32 unter Kenntlichmachung der Zusätze Steinhöwels durch Sperrdruck, 212-215 kleines Glossar, 181 Abbildung des ArztHolzschnittes.

${ }^{9}$ Einige weitere sachliche Zusätze bei Borvitz, (wie Anm. 1) $128 \mathrm{ff}$. - Besondere Aufmerksamkeit verdienen die umfangreichen Ergänzungen in c. 28 (Jägerei), die Präzisierungen der Vorwürfe gegen die Hirten in c. 30 und im Theatrica-Kapitel (c. 31) die Ausführungen über das Schwerterspiel, das Stechen und das ocbssen spil zu Rom oder das schwein spil czu Nürnberg. 
wircket. We euch, die es thund. We aber der oberkeyt, die söllichs waißt vnnd nit straffet. $O$ wie offt werdent die gewand durch die walcker verderbet mit vnfleiß der erden oder warmes wasser in rechter zeit zugeben. Wie offt aber die gewand ferber weinstein fur aland vnd kalack für weidisch zu der langen brauchen, vnd wie sy mit der waid, bintfarb vnd rot vmb gangen, wäre viel von zeschreiben, das ich vmb kurtzi, auch darumb, das ich sy an irem glimpff nit zebarte letze, vallen lasse. Wie sich aber die schneyder haltent, gethar ich nit so lauter schreiben, aber der gemein leumbt beweyset es. Leg dartzu die bösen fein der halben wambas, außgeschnitten röck, abgeschnitten goller, daruon die bels nit bedecket werden, ond vil des geleychen. Ich geschweyg der schand pletzen, die zu den abschnitzlin in den korb vallent, darauß sy goller ond decklachen machent. Man sol schweygen, ich mein nun die, die es thund. Wie die leinen vnnd barchant weber, wie offt wirt daz klein garen abgetragen vnd $d z$ grob dar für gegeben. $\mathrm{O} b$ daz ein diebstal seye, laß ich dich vrteylen. Wie offt erfüllet die schlichti das verstolen garen. Ich red zunil. Betrachte ein yeder das ubrig selber. Was listes aber die barchant weber suchent, beweysen die gestraffte tuch yetz in vberzwerch, dann in die lenge gar zerschniten, vnn straff des geltes. Die bößlist vnnd behendigkeyt der kursener will ich vallen lassen, wann ee das ich erzelte das valsch ferben der merder, zöbel vnd biber. Daz kreiden des fechs wol zegrä̈wen, $d z$ ubermächtig baissen der merder, fuchs vnd anderer mit den weinheffen, daz auß tenen der kursenen über rechte maß, vnzeitigs vnder das zeitig zunermischen, vnd auß hundertfältiger trügnuß vergienge die zeyt...

Mag Steinhöwel mit dem eben wiedergegebenen Abschnitt den Fachleuten der Handwerksgeschichte kaum Neues zu vermitteln, so dürften vielleicht seine $\mathrm{Zu}$ sätze bei der Kritik des schmid werck in c. 26 bei Technikhistorikern auf Interesse stoßen: Lateinische Fassung: ... Fabri vero plerunque sophistica non vera fabricant, blandos vomeres cudunt, blanda arma atque infidelia, molles gladios et plerunque toxicatos conficiunt, carius fabrilia sua vendere conantur quam valeant. Rursus arma vendunt infidelibus, nec sua arte contenti alienas inquirunt. De quibus ait Ysaias [40,19], nunquid sculptile conflabit faber. O quot falsas ferri fabricaciones et pro calibe communtaciones; quot sophisticata ferramenta, quot falsas cementaciones, quot lapides lignorumque sculpture et picture falsas operaciones machinantur. Aurifices vero, quot metallorum falsas connexiones, quot sophisticationes, quot dealbaciones, quot deceptorias alchimicasque operationes nec repertas transmutationes, quot metallorum et monetarum falsas commutaciones, quot inutiles et caducas deauraciones, picturas et coloraciones, auricalci pro auro, stanni pro argento pestiferas vendiciones. Quot mineralium falsas perscrutationes agant et conficiant, non facile dicere possemus...

Deutsche Fassung: ... O wie vil vntrew erzeygent die schmid in allen irem wircken: alt verrostiget eisen für neuwes, herts für geschmidigetz, dannoch übel gewürcket hinzegeben. $O$ wie vil eisnin harnasch vnnd wauffen werdent für stächlin hingegeben, die keinen stabel wann des hamers nie berüret hat. $O$ wieuil wafen werdent den veinden czesteuwer wider die freunde gemachet vnd verkaufft. Die goldschmid seind gantz lauter vnnd reyn vor allem bößlist vnnd vntreure, wann ir 
keyner logieret weder gold noch silber, dann geschworner leig. Ir keyner gibt gold für zwenundzweintzig krat am strich, das nit achtzeben behaltet. Ir keyner braucht weder kupffer wasser, salmiax, aland noch schwebel, das gold zebayssen, das die streichnadeln betrogen werdent vnd von zweintzig schein das kaum balb gold ist. Ir keiner verkaffet glas für stein. Ir keiner wigt das krut vndter den versöczten steynen für gold. Ir keyner brauchet mer spangrün noch saltz, das gold zeferben, das es durch falsche varbe höcher verkäffet werde. Sy habend das gemayn sprichwort gantz zerugk gestossen: Burias vnd schablot helffent dem goldschmid auß aller not. Sy cementeren völligklich vntz auff die gläntzi de feüwers blick. Vnd on zweinel, so dise vnd tausenterlay andre lïst von inen hie zeland vermitten werdent, die noch auff disen tag ettlich goldschmid in der verren india treibent, vnnd alleyn gemainen nutz vnd eygne narung zu notturft suchent, so werdent sy billich sälig vnd wandels frey genennet. Die schlosser machent nit mer nach schlussel. Iere scbloß seind alle wol besöczet nach den schröten vnd kerfen der schlussel. Sy geben keyn schloß für den diettrich hin, das man mit einem pfriem auf möchte schliessen, dem schloß on schaden. Noch keyner sölicher vntrüw pflegent sy. Darumb will ich nicht von in schreiben. Es fäl dann, sprach bruder utz, wann kommts darzu er thuts. (Im Autograph folgt ein im Druck durch Zeilensprung ausgelassener Satz: Die rotschmid bindend nit mer kupfer farben, $d z$ es dem messing gelych sebe.) Die kanttengiesser machent allen iren czug auff das zebend als inen gesöczet ist. Nit mer als vor zeitten. Ich gethar nit vil reden von denen, die das gesatz nit verstunden, die neun pfund blei namen vnd ein pfund zin für ein pfund blei vnd neun pfund zin. Doch was inen der wismat nicht vnhilfflich czu dem klange. Obo das grössest ist von den genaden gottes gantz vernichtet. Vor zcitten in der alten ee ward souil vntrïw, falscherei und böß lïsts in den muntzen gepflegen, das keyn alter kössel sicher was, er mußte czerschnitten vnd mit ettlicher berren zeychen, ich nenn niemant, gemörcket werden, das man seben möchte, das der herr vnd die müntz geleich gut wärent. Nun ist es lauter worden. Die pfennig sein von seinem silber (Autograph hat gestrichen: luter, dann fynem oder synem silber) mit kleinem zusatz. Wann der selb daruon kommbt, so wegent dreu pfund pfennig ein ölkörnlin eins silbers. Man bricht keynen alten guldin, das man ringer darauß mache. Man feinert alles schwaches gold, vnd machet es von vierundzweintzig, das nieman gelaychet werde, vnd wirt alle müntz so kundtlich gebössert, das der herren vnnd der müntzmeyster beutel geschwellent, ond des gemaynen mans beutel ethicam gewinnent. $O$ wie gütt vnnd götllich wäre, artznei dafür zesuchen. Schweig, rede nicht czunil...

Eine zweite Übersetzung ins Deutsche hat jüngst Nikolaus Henkel entdeckt ${ }^{10}$. Sie ist nur handschriftlich überliefert. Angeregt hat sie der hochgelerte man / vom Dorn Christoff, also möglicherweise der 1474 verstorbene herzogliche Kanzler

10 Nikolaus Henkel, Ein neues Übersetzungswerk des deutschen Frühhumanismus, in: ders. (Hrsg.), Bücherschätze in Regensburg. Frühe Drucke aus den Beständen der Staatlichen Bibliothek, hrsg. von dems. (Regensburg 1996) 39f.; vgl. auch Anhang 1, A, b, Nr. 2. 
und Rat Ludwigs des Reichen von Bayern - Landshut, Christoph Dorner ${ }^{11}$. Verfaßt hat sie Hanns vom Krachen perg, den Henkel identifizierte als Johannes Krachenberger, ein Kanzleibeamter Kaiser Maximilians I., der später zum Humanistenkreis um Konrad Celtis gehörte. Es wäre sicher eine lohnende Aufgabe, diese ,bayerische Übersetzung mit der lateinischen Vorlage und mit der gleichzeitigen oder doch nur wenig späteren, schwäbischen 'Übersetzung durch Steinhöwel zu vergleichen. In diesem Zusammenhang wäre auch zu überprüfen, ob wirklich der Johannes Krachenberger aus Vilshofen bei Passau, der sein Studium im Winter 1475 in Wien begann ${ }^{12}$, im August 1488 in den Matrikeln der Universität Ingolstadt auftaucht ${ }^{13}$, bald darauf Sekretär an der kaiserlichen Kanzlei in Linz wurde, 1497 Protonotar in Österreich und Rat des Kaisers, mit dem Hans von Krachenperg personengleich ist, der seine Speculum-Verdeutschung spätestens $1474 \mathrm{dem}$ Christoph Dorner vorgelegt haben müßte. Es erscheint doch wenig glaubhaft, daß ein junger Mann vor seinem Studium fähig gewesen sein soll, einen so umfangreichen lateinischen Text zu übersetzen, dabei auch lateinische Verse zu dichten und „höchst anspruchsvolle deutsche Strophen zu verfassen“14.

$11 \mathrm{Zu}$ Dorner vgl. Heinz Lieberich, Die gelehrten Räte. Staat und Juristen in Baiern in der Frühzeit der Rezeption, in: ZBLG 27 (1964) 120-189, hier 128 f.; ders., Klerus und Laienwelt in der Kanzlei der baierischen Herzöge des 15. Jahrhunderts, in: ZBLG 29 (1966) 239-258, hier 247.

12 Vgl. Die Matrikel der Universität Wien 2, 1451-1518, I (Publik. d. Inst. f. Österr. Gesch.frschg. 6,1,2, Graz, Köln 1959) 152.

13 Vgl. Hans Rupprich (Hrsg.), Der Briefwechsel des Konrad Celtis (Veröff. d. Komm. z. Erfrschg. d. Gesch. d. Ref. u. Gegenref., Humanistenbriefe 3, München 1934) 50f., Anm. 1, unter Hinweis auf Georg Wolff, Die Matrikel der Universität Ingolstadt 1472-1500 (München 1906) 185. - Der Briefwechsel enthält auch mehrere Schreiben von Johann Krachenberger in deutscher Sprache, die helfen könnten, seine Identität mit dem Arévaloübersetzer zu verifizieren oder zu falsifizieren.

${ }^{14}$ Henkel, (wie eben, Anm. 63) 40. 


\section{Anhang 3}

\section{Die Abbildungen}

Dem ersten Druck der Übersetzung Steinhöwels ${ }^{1}$ wurden 57 Holzschnitte beigefügt, die gewiß den Umsatz steigern sollten. Die Druckstöcke oder Nachschnitte fanden sodann Verwendung nicht nur in den weiteren Ausgaben der Verdeutschung, sondern auch in Übertragungen, die für das spanisch oder französisch lesende Publikum gedacht waren ${ }^{2}$. So gekonnt, eindrucksvoll und informativ erschienen die Abbildungen, und zwar besonders die zwölf der artes mechanicae, daß sie in neuerer Zeit häufig zur Illustration von Büchern und Aufsätzen variantenreicher Thematik genutzt werden, zumal sie durch das Handbuch von Schramm seit 1920 leicht zugänglich sind ${ }^{3}$. Die Entwicklung ihres Eigenlebens

1 Vgl. Anhang 1, B, b, Nr. 1.

2 Vgl. Anhang 1, B, c (span.) bzw. 1 B, d (franz.). 39 Abbildungen aus dem spanischen Druck sind wiedergegeben bei Francisco Vindel, El arte tipografico en España durante el siglo XV. [4] Zaragoza (Madrid 1949) 126-132.

3 Albert Schramm, Der Bilderschmuck der Frühdrucke, 2. Günther Zainer (Leipzig 1920) 22f. (Angabe der Blätter und der zu den Holzschnitten gehörenden Kapitelüberschriften), auf Tafel 93-100 die Abbildungen 699-754 (Abb. 700 mit zwei Holzschnitten); Abb. 720-731 betr. die Handwerke. Der Faksimile-Teildruck von 1908 der Ausgabe vom 23. Juli 1479 (vgl. Anh. C, b, Nr. 1) bietet $54 \mathrm{Abb}$. Es fehlen mit dem deutschen Widmungsvorwort die Holzschnitte mit dem Stammbaum und den Wappen sowie der im Spiegel zum zweiten Mal plazierte Holzschnitt zum Ackerbau (Schramm, 720). - Ausgewählte Beispiele in alphabetischer Reihenfolge für die Nutzung, die sich teils auf den Druck von Zainer, teils auf den durch Bämler bezieht, mit den entsprechenden Nummern bei Schramm in Klammern: Otto Borst, Alltagsleben im Mittelalter (Insel TB 513, Frankf. a.M. 1983) Abb. 19 (709), 21 (720), 25 (713); Karl Brunner, Gerbard Jaritz, Landherr, Bauer, Ackerknecht (Wien u. a. 1985) Abb. 28 (720); Johannes Bübler, Die Kultur des Mittelalters (Leipzig 1931) Abb. 17 (724); Siegfried Epperlein, Der Bauer im Bild des Mittelalters (Leipzig u. a. 1975) Abb. 131 (703); Fischel, (wie unten Anm. 7) Abb. 9 (720 u. 727); Rolf Hellmut Foerster, Das Leben in der Gotik (München, Wien, Basel 1969) 170 (713); Deutsche Geschichte 1 (Berlin 31974) 352 (731) u. 377 (703); Deutsche Geschichte in Bildern von der Urzeit bis zur Gegenwart, hrsg. von Herbert Jabnkubn, Hartmut Boockmann und Wilbelm Treue (Wiesbaden 1981) Abb. 220 a (705); Ein mittelalterliches Hausbuch. Praktischer Ratgeber für Familie, Haus und Garten, hrsg. von Tania Bayard (Freiburg i.Br. 1992) Abb. 36 (705), 105 (720), 113 (728), 139 (731); Franz Heinemann, Die Richter und die Rechtsgelehrten. Justiz in früheren Zeiten (Leipzig 1900, ND Düsseldorf, Köln 1969) Abb. 55 (719) u. 56 (ähnl. 706); Paul Herre, Deutsche Kultur des Mittelalters in Bild und Wort (Leipzig 1912) Abb. 214 u. 215 (723, 724); Friedrich Klemm, (wie oben Anm. 1) Abb. 50 (723, 724, 730); Harry Kübnel (Hrsg.), Alltag im Spätmittelalter (Graz u. a. 21985) Abb. 40 (723), 71 (724), 216 (734); Karl-Heinz Ludwig, Volker Schmidtchen, Metalle und Macht (Propyläen Technikgeschichte 2, Berlin 1992) Abb. 137 (724); Ernst Mummenhoff, Die Handwerker in der deutschen Vergangenheit (Die deutschen Stände in Einzeldarstellungen, Leipzig 21924, ND $\left.{ }^{3} 1979\right)$ Abb. 8 (724), 9 (722), 19 (723); Hermann Peters, Der Arzt und die Heilkunst in alten Zeiten (Leipzig 1900; ND Düsseldorf, Köln ${ }^{31979)}$ Abb. 14 (730); Heinrich Pleticha, Bürger - Bauer - Bettelmann (Würzburg 1971) Abb. 154 (720); Emil Reicke, Magister und Scholaren. Illustrierte Geschichte des Unterrichtswesens 
ging so weit, daß sich in einer jüngst erschienenen Studie zur handwerklichen Lehre zwar alle einschlägigen Holzschnitte wiederfinden, im Text jedoch auf Arévalo/Steinhöwel mit keinem Wort eingegangen wird ${ }^{4}$. Eine Übersicht über Bildbeispiele von Szenen der septem artes mechanicae vom Beginn des 13. Jahrhunderts bis zum frühen 16. Jahrhundert einschließlich der Illustrationen in Arévalos/ Steinhöwels Spiegel hat jüngst Johannes Zahlten geboten 5 . Sie muß deshalb hier nicht von neuem erstellt werden.

Aus buch- und kunstgeschichtlicher Sicht hat 1923 Ernst Weil den grundlegenden Beitrag zum Verständnis der Holzschnitte in den ersten beiden Drucken des Spiegel geleistet ${ }^{6}$. Korrekturen und Ergänzungen hat vor allem Lilli Fischel (1963) beigesteuert ${ }^{7}$. Demnach sind Johannes Zainer, der aus Straßburg stammende erste Ulmer Drucker, und Heinrich Steinhöwel um 1470 in Ulm näher zusammengekommen, wo Johann Zainer eine ganze Reihe der Übersetzungen Steinhöwels mit Illustrationen veröffentlichte. Daß der erste Druck des Spiegel nicht in Ulm, sondern in Augsburg bei Günther Zainer erfolgte, sei vermutlich auf eine damalige Überlastung der Augsburger Offizin zurückzuführen. Näher liegt es vielleicht, daran zu erinnern, daß auch die lateinischen Fassungen des Speculum nicht bei

(Leipzig 1901, ND 31979) Abb. 6 (734), 7 (736), 12 (732), 41 (733), 42 (734); Christoph J. Scriba, Bertram Maurer, Technik und Mathematik, in: Technik und Wissenschaft (Technik und Kultur 3, Düsseldorf 1991) 46f. (723-727 u. 729, 730); Christoph Schmidt, Leibeigenschaft im Ostseeraum (Köln u. a. 1997) Umschlag (721); Georg Steinhausen, Kaufleute und Handelsherren in alten Zeiten (Leipzig 1899, ND Düsseldorf, Köln ${ }^{31979)}$ Abb. 22 (731); Sudhoff, (wie Anh. 2, Anm. 8) Abb. 181 (730); Vindel, (wie Anm. 2); Weil, (wie unten Anm. 6) Abb. 11-15 (707, 720, 722, 729, 734); Zablten, (wie unten Anm. 5) Abb. 11-20 (720726 u. $728-730$ ).

${ }^{4}$ Flachenecker, (wie oben Anm. 1) Abb. 7-10 (Schramm 722-731).

5 Johannes Zablten, Humana inventa. Zur künstlerischen Darstellung der artes mechanicae, in: Scientia und ars (wie oben Anm. 58) 1008-1022; wichtige Literatur wie die Arbeiten von A. Wirth, (siehe oben, Anm. 69) und G. Binding, (Art.) Arbeitsbilder. 1. Westen, in: Lex. d. MAs 1 (1980) 883-887 bleibt unerwähnt. Zablten referiert über das Musterbuch des Zisterzienserklosters Rein bei Graz (1208-1213), eine Handschrift von Brunetto Latinis ,Livre dou Tresor' (um 1300), die Reliefmedaillons von Giottos Campanile in Florenz (1337), die Fresken des Ambrogio Lorenzetti in der Sela della Pace des Palazzo Publico in Siena (1338/40), eine Miniatur in einer heute in Den Haag aufbewahrten Nicolaus-Oresme-Handschrift, die für Karl V. in Paris angefertigt wurde, den Holzschnittzyklus aus unserem Spiegel, den Wissenschaftsstammbaum in Gregor Reischs, Margarita philosophica' (siehe oben Anm. 69) und Celtis, Burgkmair, (siehe oben Anm. 70).

${ }^{6}$ Ernst Weil, Der Ulmer Holzschnitt im 15. Jahrhundert (Ulm 1923) bes. 22-38.

7 Lilli Fischel, Bilderfolgen im frühen Buchdruck. Studien zur Inkunabel-Illustration in Ulm und Straßburg (Konstanz, Stuttgart 1963). Arévalos/Steinhöwels Spiegel interessiert sie nur am Rande; im Mittelpunkt stehen Untersuchungen zu den Illustrationen von Boccaccios De claris mulieribus und vom Aesop. Versuche, einen „Boccaccio-Meister“ aufzustellen, sind nach ihrer Meinung fruchtlos (S. 34). Ausgesprochen niederländische Schulung bestätigt sie dem von Weil als "Zamorensis-Meister" bezeichneten Mann. Insgesamt sieht sie in den Holzschnitten des Spiegels im Vergleich zur Aesop-Folge ein "Schwächerwerden des Physiognomischen, ein Stereotypwerden der Gewandformen und des plastischen Empfindens überhaupt“ (S. $61 \mathrm{f}$.). 
Johann, sondern bei Günther Zainer gedruckt wurden ${ }^{8}$. Die Holzstöcke sollen in Ulm, wohl unter den Augen Steinhöwels entstanden sein. Sind die ersten Schnitte noch dem bekannten Bocaccio-Meister oder seinen Vorzeichnungen zuzuweisen, so wird, vornehmlich bei den Handwerksdarstellungen, ein neuer Holzschneider greifbar, von Weil als "Zamorensis-Meister" bezeichnet ${ }^{9}$.,Die mondäne Eleganz (seiner) langen dürren Gestalten weist über das oberdeutsche Gebiet hinaus " ${ }^{10}$, so daß die Annahme, einen niederländischen Zeitgenossen vor sich zu haben, sehr wahrscheinlich wird. Johann Bämler hat die Stöcke 1479 in seiner Ausgabe verwendet ${ }^{11}$. Nach ihm benutzten sie in Lyon 1482 Philippi und Reinhard ${ }^{12}$, schließlich 1491 Hurus in Zaragoza ${ }^{13}$, während Peter Berger in Augsburg 1488 nicht umhin konnte, für seinen Nachdruck neue Holzstöcke herzustellen ${ }^{14}$.

${ }^{8} \mathrm{Vgl}$. Anhang 1, B, b, Nr. 1 u. 2. - Bei Günther Zainer waren auch die beiden ersten Drucke von Steinhöwels ,Griseldis‘ (1471 u. 1471/72) und seine Übersetzung des Prosaromans von König Apollonius von Tyrus (1471) erschienen; s. außer Fischel, (wie Anm. 7) auch Hess, ,Griseldis' (wie Anh. 2, Anm. 3) 50f. u. Peter Amelung, Humanisten als Mitarbeit der Drukker am Beispiel des Ulmer Frühdrucks, in: Fritz Krafft, Dieter Wuttke, (Hrsg.) Das Verhältnis der Humanisten zum Buch, (Komm. f. Hum. Forschg. Mitt. 4, Boppard 1977) 129-144, hier 132. Weniger überzeugt der Hinweis auf Steinhöwels Verbundenheit mit Augsburg "durch die Herkunft seiner Frau" bei Horst Kunze, Geschichte der Buchillustration in Deutschland. Das 15. Jahrhundert (Leipzig 1975) 258. - Zum Verhältnis Steinhöwels zu Günther und Johann Zainer, leider ohne Hinweis auf die Speculum-Übersetzung, vgl. Amelung, (wie eben) passim; bezeichnend mag auch sein, daß Steinhöwels Esopus lat./dtsch. um 1476/77 bei Johann und die deutsche Separatausgabe um 1477/78 bei Günther Zainer gedruckt wurden; vgl. GW 351 u. 352 sowie Dicke, (wie Anhang 2, Anm. 7).

9 Zur Aufteilung der Holzschnitte auf den Boccacio- bzw. Zamorensis-Meister vgl. Weil, 107 Anm. 47.

10 Weil, 29.

11 Weil, 107 Anm. 46; vgl. auch Anhang 1, B, b, Nr. 3.

$12 \mathrm{Vgl}$. Anhang 1, B, d, Nr. 3.

$13 \mathrm{Vgl}$. Anhang 1, B, c, Nr. 1.

$14 \mathrm{Vgl}$. Anhang 1, B, b; Nr. 4. 
